\title{
Hacia una arqueología de los nuevos imaginarios culturales. Autores, temas e ideas
}

Towards an archaeology of the new cultural imaginings. Authors, topics and ideas

Joan Prat Carós

Catedrático emérito de Antropología Social . Universitat Rovira i Virgili (Tarragona)

joan.prat@urv.cat

30 ANIVERSARIO DE LA GAZETA DE ANTROPOLOGÍA

NÚMERO COORDINADO POR FRANCISCO CHECA OLMOS Y CELESTE JIMÉNEZ DE MADARIAGA

RESUMEN

En el artículo se abordan las fuentes (autores, temas e ideas) que constituyen el entramado teórico sobre el que se asientan los nuevos imaginarios culturales, comúnmente denominados 'New Age' o 'nebulosa místico-esotérica'. El texto finaliza con una rápida evaluación de la literatura antropológica y sociológica española sobre el tema.

\section{ABSTRACT}

This article looks at the sources (authors, topics, and ideas) that make up the theoretical framework behind the new cultural imaginings commonly referred to as 'New Age' or 'mystical-esoteric nebulousness'. The text concludes with a quick review of the Spanish anthropological and sociological literature regarding the subject.

PALABRAS CLAVE

imaginarios culturales | nueva era | autores | temas | ideas

KEYWORDS

cultural imaginings I new age I authors I topics I ideas

\section{Introducción}

James Frazer (1854-1941), uno de los grandes etnólogos evolucionistas, predijo que todas las sociedades humanas tenían que pasar por tres grandes etapas -la mágica, la religiosa y la científica-, en un proceso evolutivo de carácter lineal. Según parece, estaba convencido de que las sociedades occidentales estaban plenamente instaladas en la fase científica. Sin embargo, el arte de la predicción, como el de la profecía, es una técnica arriesgada, pues si echamos un vistazo a nuestro alrededor todo parece indicar que Frazer iba muy desencaminado ya que, si bien es cierto que las religiones hegemónicas han perdido el papel político, cultural y simbólico que habían tenido hasta los años setenta del siglo XX (proceso conocido en la ciencias sociales como "secularización" o "desencanto del mundo"), no lo es menos que, contra todo pronóstico, después de la segunda guerra mundial, se ha producido un "reencanto del mundo", que incluye un amplio abanico de significados y fronteras inciertas. Esta proliferación de prácticas, creencias e imaginarios ha recibido distintas denominaciones: new religion and healing movements (Beckford 1984), nebuleuse mystique-esoterique (Champion 1989, 1990, 1993, 1994; Prat y Moreno 2007), creencias y prácticas místicas y esotéricas (Siqueira 2004); New Age (Wasson 1992, Lewis 1992, Heelas 1996, Hanegraaff 1998, Campo 2010); Nueva Era (Carozzi 1999, Escandell 2005, Merlo 2007); nuevas espiritualidades; religiosidades emergentes (Mardones 1997); nuevas formas de espiritualidad (Griera y Urgell 2002, Lenoir 2003, Fedele 2008); nueva consciencia espiritual (Redfield 1997), etc. También hemos escuchado, en referencia al ámbito de estudio que nos ocupará, las expresiones la identidad de lo alternativo (Téllez) o el mercado de la insatisfacción 
(Pujadas); y nosotros optamos por la denominación de nuevos imaginarios culturales que, a su vez, nos ayudó a constituirnos como Grupo de Investigación sobre Imaginarios Culturales (GRIC) para llevar a cabo una investigación colectiva a la que me referiré más adelante.

En el otoño de 2006 empezamos a plantearnos una serie de interrogantes, más bien primarios, que nos ayudaron a perfilar la reflexión sobre el nuevo objeto de estudio que nos rondaba por la cabeza. Eran interrogantes del tipo:

1. ¿Por qué muchas iglesias se han quedado vacías y, en cambio, los cursos de vipassana, de yoga kundalini o de reiki se llenan sin ningún tipo de dificultad?

2. ¿Por qué la plegaria del Santo Rosario de toda la vida (en este punto recordábamos la campaña del padre Peyton, para quien "la familia que reza unida, permanece unida") ha caído en picado y se encuentra bajo mínimos, mientras se recitan con entusiasmo los mantras hindús, tibetanos, sijs, sufís o de la cábala judía?

3. ¿Por qué las típicas imágenes de San Pancracio, San Antonio o el Sagrado Corazón de Jesús, las estampas de María Inmaculada, los clásicos y variados crucifijos o los cuadros de la Santa Cena se han visto complementados, cuando no sustituidos, por las imágenes de Buda, Krishna, el elefante Ganesha o Hanuman (el dios mono) o por figuras, calendarios o banderolas de las estupas tibetanas?

4. ¿Por qué las fotografías de los papas felizmente reinantes -Juan Pablo II hasta su muerte y después Benedicto XVI- comparten protagonismo con personajes tan carismáticos como el Dalai Lama o Amma, la que ofrece darshan y abraza al personal de medio mundo?

5. ¿Por qué el Dalai Lama -continuando con el punto anterior-, en septiembre de 2007, llenó hasta la bandera el Palau Sant Jordi de Barcelona, con una capacidad de más de 12.000 asientos, cobrando una entrada de 22 € por persona? Haciendo un cálculo rápido se recogieron 264.000 euros, casi 44 millones de las antiguas pesetas, lo que desde luego no es broma.

6. Amma, en su visita anual a la ciudad de Barcelona, también reunió en uno de estos recintos multitudinarios a una multitud enfervorecida. La gurú abrazó a quien escribe estas páginas después de hacer cola durante cuatro horas. ¿Cómo y por qué este intenso fervor podía ser compatible con el activísimo merchandising que se desplegaba en el mismo espacio sin ningún tipo de problema?

7. ¿Por qué en muchas casas la típica Biblia y el Nuevo Testamento de toda la vida (y otros libros de devoción o de literatura edificante) comparten hoy espacio con textos de espiritualidad hindú, china, tibetana o japonesa, o bien con textos sufís o de la cábala judía? Tampoco es infrecuente encontrar en algunas de ellas ejemplares del I Ching, el Bhagavad Gita, El Libro del Tao, El Zohar, El Libro del Té o las compilaciones de haikus del Zen.

8. ¿Por qué Madonna o Paulina Rubio son unas forofas de la cábala; John Travolta o Tom Cruise, de la cienciología; Richard Gere, Maria del Mar Bonet o la baronesa Tyssen, del Dalai Lama; y la familia de músicos Claret, de Amma? No olvidemos tampoco que Françoise Hardy escribe best sellers de astrología y que Shirley MacLaine es una de las grandes figuras del New Age y el esoterismo.

9. ¿Por qué los libros de Paulo Coelho, Alejandro Jodorowski, Jorge Bucay (o de James Redfield, Brian Weiss o Deepak Chopra, por no citar a Osho) se venden como rosquillas?

10. ¿Quién no conoce a gente de su entorno que ha viajado a la India, al Nepal o al Tíbet (si ha sido posible) atraída por la fascinación de Oriente y por sus vías de meditación y de iluminación?

11. ¿Quién no ha escuchado en alguna ocasión una serie de conceptos que nos han llegado de Oriente y que se han incorporado a nuestra cotidianidad? Sirvan como ejemplo las siguientes palabras, ordenadas alfabéticamente: asana, bhakti yoga, brahman, chacras, chi kung, Dalai Lama, darshan, Dharma, gurú, hatha yoga, Kali Yuga, Kama Sutra, karma, karma yoga, kundalini, kundalini yoga, lingam, mandala, 
mantra, maya, moksha, mudra, nirvana, om, pranayama, prasadam, puja, reiki, rimpoche, sadhu, samadhi, samsara, Sangha, sexo tántrico (vulgarmente "polvo" tántrico), swami, taichí, tantra, Tao, taoísmo, Veda, vipassana, yang, yin, yoga, yogin, zazen, zen...

Hasta aquí el mundo de las espiritualidades. Sin embargo, los interrogantes podrían hacerse extensivos a quienes van con el botecito de flores de Bach o de rescate (Rescue) en el bolso de mano y optan por la homeopatía, la bioenergética o las terapias holísticas; o también, en otra dirección perfectamente compatible, a quienes se hacen leer las cartas del tarot, siguen las indicaciones de su carta natal (astral), que algún experto ha confeccionado para ellos, y confían en la información contenida en los registros akásicos que se han hecho abrir a través de algún experto en la canalización o el mediumnismo.

Dos años después de haber iniciado la reflexión sobre estas y otras cuestiones estrechamente relacionadas, en el otoño de 2008 comenzamos a elaborar un proyecto colectivo para abordar desde una perspectiva antropológica ese mundo abigarrado. Un buen libro de Vicente Merlo, La llamada (de la) Nueva Era. Hacia una espiritualidad místico-esotérica (2007), nos resultó de gran utilidad en esa etapa, pues este filósofo dedica sendos capítulos de su texto a presentar la dimensión espiritual (oriental), la dimensión psicoterapéutica y la dimensión esotérica de la Nueva Era. Esos fueron los tres grandes ejes que adoptamos para organizar las entrevistas y las observaciones que configuran la monografía titulada Els nous imaginaris culturals: espiritualitats orientals, teràpies naturals i sabers esotèrics, que será editada por Publicacions URV y con los auspicios de la Generalitat de Catalunya, que financió la investigación a través del programa IPEC (Inventari del Patrimoni Etnològic de Catalunya). Si los hados son favorables el libro se presentará el 21 de diciembre de 2012.

Dada la imposibilidad de comentar los resultados de la investigación, aquí nos limitaremos a presentar algunos de los grandes autores e hitos teóricos que, en nuestra opinión, constituyen la base fundacional o la arqueología, como reza el título- sobre la que se han asentado los temas e ideas que nutren esos nuevos imaginarios culturales.

Como se podrá ver de inmediato, el espectro de autores y temas seleccionados ha sido amplio: novelistas y ensayistas como Aldous Huxley, Lynn White o Salvador Pániker; psicólogos de signo distinto, como Cal Gustav Jung y Abraham Maslow; un gurú y animador filosófico de la contracultura encarnado por Alan Watts; Carlos Castaneda, antropólogo convertido en chamán y brujo; un banquero experto en hongos alucinógenos Ilamado Robert Gordon Wasson, y un físico teórico, Fritjof Capra. También se han incluido dos libros de divulgación, Matin des magiciens (traducido al castellano como El retorno de los brujos), de Pauwels y Bergier, y The Aquarian Conspiracy, la famosa Conspiración de Acuario de Marilyn Ferguson, sin olvidar un congreso celebrado en Córdoba, cuyas actas se publicaron con el título de Science et conscience: les deux lectures de l'Univers. A todos ellos los denominaremos como "los clásicos".

\section{Los clásicos}

\subsection{Aldous Huxley: el pionero}

El primer pensador que tendremos en cuenta es el escritor y ensayista Aldous Huxley y, más concretamente, algunas de sus obras: The Perennial Philosophy (1944), Doors of Perception (1954) y, en menor medida, Moksha (1980).

Huxley inicia el primero de estos textos, traducido como La filosofia perenne (2000) (1), señalando que el concepto de philosophia perennis fue acuñado por Leibnitz, pero que la realidad a la que alude es algo inmemorial y universal. Esta filosofía se ocupa de la (auténtica). Realidad, que es una y divina y subyace tras el mundo múltiple de las cosas, las vidas y los espíritus (1948: V). Además, esta realidad no se puede abordar directa e inmediatamente, de modo que solo aquellos que son puros de corazón y pobres de espíritu -santos, profetas, sabios o iluminados- pueden captarla en toda su plenitud. El resto, incluidos los estudiosos, deben emprender una vía indirecta consistente en el estudio de la obra de aquellos que 
La entrada en este mundo de la unidad y la completitud se puede hacer por la vía inferior (la práctica y la moral), que fue la elegida por aquellos que, como Buda, estaban estrictamente interesados en regular la vida práctica y rechazaban cualquier tipo de especulación. En cambio, la vía superior es la preferida por aquellos filósofos y teólogos que han hecho del pensamiento y la reflexión teórica su vocación. Entre unos y otros están los que se acercan por la vía del medio -la de la "religión espiritualista"-, que incluye a los contemplativos y místicos de todos los tiempos, tanto de Oriente como de Occidente. Esta es precisamente la vía que elige Aldous Huxley para presentar y glosar la filosofía perenne. Así, compone una antología muy personal y variada de grandes textos sagrados pertenecientes a las más diversas tradiciones místicas, con claras preferencias por algunos de los shadus excepcionales de la India, como Shankara o Sri Aurobindo, o los clásicos Bhagavad Gita y el Srimad Bhagavatam; también es notable la alusión a los textos budistas del Dhammapada o al Libro tibetano de los muertos, así como a las obras de los sabios chinos Laozi y Zhuangzi. El pensamiento de los místicos sufíes es asimismo glosado principalmente a través de los textos de Jalal al-Din Rumi o Al- Ghazzali; sin olvidar, evidentemente, los místicos cristianos, católicos o protestantes, como el maestro Eckhart, san Juan de la Cruz, santa Teresa de Jesús, santa Catalina de Siena o Ruysbroek y William Law. Estos autores y textos, y muchos otros, le sirven a Aldous Huxley para ilustrar los diferentes temas específicos que, a su juicio, integran esta filosofía de todos los tiempos.

Pocos años después, el mismo autor publicaba otra obra capital, Doors of Perception (1954), traducida al castellano con el título de Las puertas de la percepción (1956).

Tras una breve alusión a Ludwig Lewin, primer estudioso del peyote, y Havelock Ellis, interesado por la mezcalina (el principio activo del peyote), Huxley dedica su libro a explicar un experimento de ingesta de mezcalina que realizó en un laboratorio de California. Este tenía como objetivo primario conocer desde dentro un estado no ordinario de consciencia como los que suelen vivir los visionarios, los médiums o místicos cuando, por medios naturales, por hipnosis o autohipnosis, por la práctica de la meditación sistemática o por la ingesta de la droga adecuada, sobrepasan el estado de discernimiento convencional para entrar en lo que se denomina "estados de consciencia modificada o expandida".

Huxley, con indudable maestría, describe su experiencia visionaria, en la que juegan un papel clave los colores, la indiferencia frente al espacio y el tiempo, unas impresiones visuales muy intensas y una percepción extrasensorial que le conducen hasta una belleza contemplativa que vive con profundo sentimiento de unidad y que expresa diciendo: "hay un 'oscuro conocimiento' de que Todo está en todo, de que Todo es realmente cada cosa" (1956: 33, la traducción es nuestra).

Gracias a la mezcalina o con su ayuda, el escritor se acerca al insondable misterio del puro ser interior que tantos artistas o escritores han experimentado -el ejemplo de William Blake con sus libros proféticos sería el paradigma por excelencia- y la mirada hacia el mundo exterior se convierte en la del visionario sumergido en el estado del mysterium tremendum et fascinans, según la famosa expresión de Rudolf Otto.

La última parte del libro incluye una reflexión más sociológica, en la que Huxley comenta el deseo de tantos hombres y mujeres de diferentes épocas y culturas de alcanzar esos "paraísos artificiales" tan deseables cuando las existencias vividas son pobres, limitadas y monótonas. El afán de escapar de uno mismo y del ambiente intolerable que le oprime serían los motivos principales -siempre según Huxleypara tomarse estas "vacaciones químicas" logradas a través del alcohol, las píldoras y los barbitúricos, el opio, el hachís, la marihuana y la coca, productos que, en diferentes ambientes y culturas, pueden actuar como sustitutivos de los sentimientos religiosos.

En la misma línea cabe situar Moksha, subtitulado en castellano Escritos sobre psicodelia y experiencias visionarias 1931-1963, una compilación de textos en forma de artículos, cartas o reflexiones diversas sobre las drogas que escribió Huxley, principalmente, en la última década de su vida. La compilación, a cargo de M. Horowitz y C. Palmer (2007), cuenta con un prefacio de Albert Hofmann y una introducción 
de Alexander Shulgin, dos famosos bioquímicos, el primero descubridor del LSD, y el segundo, sintetizador de un gran número de sustancias alucinógenas y enteógenas.

\subsection{Carl Gustav Jung: la sincronicidad}

En 1952, el psiquiatra suizo Carl Gustav Jung, seguidor heterodoxo y cismático de Freud, publicó Sincronicidad como principio de conexiones acausales (2004). En este escrito, Jung plantea la tesis de que, si bien el mundo occidental acepta mayoritariamente el principio de causalidad como una de las leyes naturales más consistentes, hay fenómenos en el mundo que no obedecen tanto a la causalidad como a la casualidad. Según este autor, no es infrecuente que en el mundo físico, el de las pequeñas magnitudes, se produzcan eventos que funcionan con una especie de "simultaneidad", que él califica de sincronicidad, definiéndola como "una coincidencia temporal de dos o más sucesos relacionados entre sí de una manera no causal, cuyo contenido significativo sea igual o similar" (2004: 436). De este modo, la sincronicidad consta de dos elementos: "1. ${ }^{\circ}$ Una imagen inconsciente accede directamente (literalmente) o indirectamente (simbolizada o insinuada) a la consciencia como sueño, ocurrencia o presentimiento. $2 .^{\circ}$ Con este contenido coincide una situación objetiva" (op. cit., 442, subrayados en el original). Así entendida, la sincronicidad sería heredera de la antigua teoría medieval de la correspondentia e, incluso, de la más antigua concepción mágica, según la cual existe un vínculo de simpatía entre todas las cosas (la llamada magia simpatética, con sus variantes de homeopática y contaminante), nociones ambas dejadas de lado desde el desarrollo de las ciencias naturales en el siglo XIX.

A pesar de ese rechazo generalizado, los ejemplos descritos por Jung son muy numerosos. Incluyen, por ejemplo, las percepciones telepáticas de la muerte de una persona; el discernimiento de acontecimientos que todavía no han tenido lugar y que posteriormente acaban reflejados en las páginas de un periódico; o el famoso caso de uno de sus pacientes: al poco de escuchar el relato de su sueño, en el que aparecía un escarabajo de oro, una cetonia (un insecto absolutamente raro en aquellas latitudes) golpeó la ventana de la consulta del psiquiatra. En otra dirección, Jung subraya algunos casos históricos, como los protagonizados por el famoso científico y visionario sueco E. Swedenborg que profetizaba acontecimientos que aún no habían sucedido, pero que acababan ocurriendo.

Otros filósofos o pensadores que ponen de relieve la existencia de fenómenos no causales son Leibnitz, con la idea de la armonía preestablecida; Schopenhauer, que hablaba de simultaneidad o casualidad; y también Avicena, Alberto Magno o Goethe. En otras culturas, como la china, se acepta sin problemas un arte adivinatorio como el I Ching, que, vinculado al taoísmo, funciona de manera intuitiva y acausal. Otros ejemplos citados por Jung, hacen referencia a los famosos experimentos del científico Rhine con individuos con facultades telepáticas, que fueron publicados en Extra-Sensory Perception.

Todo esto es posible, siguiendo el argumento junguiano, por la estructura inconsciente de los arquetipos que, como patterns of behaviour, hacen posible la sincronicidad o acausalidad. En la adenda al escrito, Jung agrupa esas coincidencias de sentidos en el tiempo en tres modalidades distintas: a) coincidencia y simultaneidad de cierto contenido psíquico con el correspondiente proceso objetivo; b) coincidencia de un estado psíquico fantasioso -visión o sueño-, que posteriormente se comprueba como reflejo aproximadamente fiel de un acontecimiento que ha ocurrido en otro lugar más o menos al mismo tiempo, y c) el mismo caso, pero con la salvedad de que el evento objetivo pasa en el futuro, mientras que la fantasía que le corresponde se está dando en el presente (2004: 506-507).

Murray Stein (2004), buena conocedora y comentarista de la obra de Jung, piensa que la sincronicidad alude al orden profundo y escondido de la unidad de todo lo que existe, al unus mundus, según el concepto del mismo autor. En él, la psique no es algo que vaya por libre; por el contrario, existe una interacción profunda entre cosmos y psique, y esto es así gracias a la instancia del inconsciente colectivo y a las imágenes arquetípicas que contiene, que hacen posible la coincidencia significativa entre eventos psíquicos y materiales, que se reflejan y materializan en la llamada sincronicidad. 


\subsection{Alan Watts: filosofías y espiritualidades orientales}

El tercer clásico que tendremos en cuenta es Alan Watts, animador filosófico, teólogo y gurú de la contracultura que en las décadas de 1950 y 1960 introdujo el zen, el taoísmo, el yoga, el vedanta y, en general, las filosofías y espiritualidades orientales en Estados Unidos y, por extensión, en Occidente.

Watts inicia The Way of Zen (1956), traducido al español como El camino del Zen (1971) (2) constatando el interés que esta rama del budismo venía despertando desde la segunda guerra mundial. Su respuesta al porqué de esa atracción es la siguiente: "ocurre que [los occidentales] estamos acostumbrados a términos absolutos, a principios y leyes firmes a los que aferrarnos para nuestra seguridad psicológica y espiritual" (2006: 12). Posiblemente por ello -continúa Watts- se ha descubierto otra forma de vida productora de cultura que, durante unos mil quinientos años, se ha sentido muy cómoda con el "vacío". En efecto, el zen posee una fuerza y un humor, así como un sentido de la belleza y el absurdo, que puede resultar tan exasperante como delicioso para los occidentales.

Tras reconocer la influencia en su propia obra del Dr. Suzuki, un japonés instalado en Estados Unidos que contribuyó a popularizar esta filosofía, Watts señala que la experiencia del zen es inaccesible por medios literarios o eruditos. De ahí que no exista una enseñanza reglada y que los maestros enfaticen frente a sus discípulos aquello de "espabila por ti mismo". Según este teólogo, en el zen se tiene siempre la sensación de que el "despertar" es algo natural, sorprendentemente obvio y que puede suceder en cualquier momento. Así, a diferencia de la tradición hindú o budista, el satori japonés, este relámpago intuitivo e iluminador, es siempre imprevisible. Asimismo, en lugar de una literatura específica hay un conjunto de anécdotas, a menudo enigmáticas, que tienen como finalidad precipitar en la mente de quien pregunta aquella consciencia repentina que conduce directamente al conocimiento búdico. De este modo, cuando la mente permanece quieta, y la consciencia vacía, se llega al fin deseado sin esfuerzo y sin una búsqueda específica. En los templos o comunidades rinzai y soto, las dos grandes escuelas históricas de esta filosofía, a veces, como dice Watts, "el zen es una disciplina que se enseña a palos" (2006: 127), método que resulta bastante sorprendente a los ojos occidentales.

En la segunda parte del libro, titulada Los principios y la práctica, Alan Watts presenta una serie de aspectos vinculados al zen, como el koan (de la escuela rinzai), la meditación zazen (sentarse inmóvil con la respiración adecuada) o las diferentes artes, como la "ceremonia del té", tocar la flauta, el dibujo a pincel, la pintura, la ballestería, la esgrima y el ju-jutsu, sin olvidar la poesía (con los famosos haikus) y, por supuesto, la jardinería.

El segundo libro que comentaremos, Tao: The Watercourse Way, publicado en 1976 y traducido sin demasiada precisión como El camino del Tao (1976 y 2006), va precedido de un prólogo de Al ChungLiang Huang, un autor chino que recuerda haber dado un curso en Esalen, en Big Sur (California), la famosa comuna de la contracultura donde Watts le había confesado que dejaría que el libro sobre taoísmo que estaba elaborando se escribiese solo. De forma parecida Elsa Gidlow, citada por el prologuista, comenta que el viejo filósofo inglés, más bien rígido, reservado y cerebral, se había dejado influir de tal manera por el taichí y el taoísmo que se había convertido en una persona extrovertida, alegre y en un sabio travieso que procuraba seguir el ideal de "El hombre del Tao [que] vive en el Tao como el pez en el agua" (Al Chung 2006: 16).

Después de una introducción en la que Watts nos habla de Joseph Needham, antropólogo especializado en la cultura china, de Lao-Tzu y del Tao Te Ching, introduce la polaridad yin-yang como el principio esencial de la filosofía china, señalando la necesidad de alcanzar la armonía de los dos principios, diferentes, pero inseparables y mutuamente interdependientes. Con todo, el quid de esta filosofía no es fácil de definir, pues, según el Tao Te Ching, "El Tao que puede expresarse no es el Tao Eterno" (Watts 2006: 63). En el tercer capítulo, titulado sencillamente "Tao", uno de los más bellos del libro, Watts explica que el Tao es el principio de todo -del ser y del no ser-; paralelamente, introduce una metáfora (que enlaza con el subtítulo del libro, The Watercourse Way) para explicar que el Tao es como el agua que fluye de manera constante por la naturaleza y el universo de forma "serenamente cíclica" en una 
especie de panteísmo naturalista estructurado en torno del $L i$, el principio de orden que Needham traduce por "modelo orgánico".

Si el Tao y el Li impregnan el cosmos, el wu-wei designa el estilo de vida de aquel que sigue el fluir del Tao sin forzar las cosas y sin invertir en ello energías conscientes, el estilo de vida de aquel que encuentra el camino que se deja caminar sin resistencia. Watts ilustra el fluir momentáneo del wu-wei con la anécdota del sabio que sueña que es una mariposa, y al despertar no sabe si es una mariposa que sueña ser hombre o al revés, pero la duda no le inquieta. La comprensión intuitiva del camino del Tao es el Te, que se experimenta en el propio interior, también sin forzarlo. Cuando Thor Heyerdal -nuevo ejemplo- se dejó llevar por las corrientes marítimas y arribó con la Kon-Tiki a las playas deseadas de la isla de Pascua lo hizo gracias a la fuerza del Te (y del Tao), que le empujaba como una especie de fluido que combinaba de forma armónica las energías exteriores e interiores.

\subsection{Robert Gordon Wasson: el hongo alucinógeno}

El 29 de junio de 1955, Robert Gordon Wasson, un conocido banquero experto en hongos alucinógenos, y un fotógrafo, Allan Richardson, participaron en una aldea mexicana de la sierra de Oaxaca, Huautla de Jiménez, de una comunión sagrada con hongos enteógenos. La ceremonia fue oficiada por una india mixteca llamada Eva Méndez (en realidad María Sabina, protagonista del libro Vida de María Sabina, la sabia de los hongos, de Álvaro Estrada, publicado en 1977 con una extensa presentación a cargo del mismo Gordon Wasson), ayudada por su hija, y de ella dieron cumplido detalle en un texto publicado en Life International, revista de gran tirada, el 10 de junio de 1957. El artículo en cuestión, titulado "Seeking the Magic Mushroom" y traducido al español como "En busca del hongo mágico", se puede consultar en Internet.

Gordon Wasson inicia su texto considerando la ceremonia como una mezcla sincrética de ritos indígenas y cristianos que consiste en el consumo litúrgico y ritual de unas setas que producen unas alucinaciones intensas a quien las mastica e ingiere. La ceremonia, en la que participaron unas 20 personas, tuvo lugar de noche en casa de un joven indio, que tenía un cargo en la municipalidad y que fue el mediador entre la curandera y los dos extranjeros. Los asistentes acudieron con sus mejores galas y Eva Méndez limpió cuidadosamente los hongos que iban a ser consumidos; después, entre oraciones, los pasó por el humo del copal. Por espacio de media hora los asistentes los masticaron lentamente. Gordon Wasson confiesa que él ingirió 12 setas que tenían un sabor desagradable y amargo y que desprendían un olor rancio y penetrante. Después se apagó la única luz que había en la estancia y cada asistente se preparó para las visiones y alucinaciones, que comenzaron poco después.

El banquero micólogo habla de visiones con formas armoniosas de colores vivos y cambiantes, de bestias mitológicas y también de la progresiva pérdida de la noción del tiempo y del espacio. Estas eran sus palabras:

"me parecía estar al margen de un mundo del que no formaba parte, un mundo con el que no podía establecer contacto. Ahí estaba yo, suspendido en el espacio, ojo penetrante, invisible, incorpóreo, que veía sin ser visto. [...] las visiones parecían más reales que cualquier objeto visto hasta entonces con los propios ojos [...]. Tuve la sensación de distinguirlo todo con absoluta claridad, sin las distorsiones de la visión corriente. Veía los arquetipos, las «ideas platónicas» que fundamentan las imperfectas imágenes de la vida cotidiana" (Wasson 2010: 4).

Mientras Wasson permanecía en esa especie de escisión esquizofrénica -según sus propias palabras-, Eva Méndez, acompañada por su hija, comenzó a entonar un hermoso cántico ritual y posteriormente danzó cadenciosamente. El autor confiesa que por primera vez entendió el significado de la palabra "éxtasis".

Tras esa primera experiencia, Gordon Wasson asistió a otras ceremonias, todas ellas hechas en congregación en la región mixteca. Después pasó a consumir los hongos enteógenos primero con su 
mujer y su hija de 18 años y, más tarde, ya instalado en su domicilio de Nueva York, con amigos tan ilustres como Aldous Huxley y Robert Graves (véase el libro titulado La experiencia del éxtasis, publicado en 2003, que recoge los textos de Huxley, Wasson y Graves, que se presentan como "pioneros del amanecer psiconáutico").

En la segunda parte de "Seeking the Magic Mushroom", Gordon Wasson explica el inicio de su interés y el de su esposa por las setas alucinógenas, y cómo viajaron por todo el mundo en busca de informaciones etnográficas y folclóricas obtenidas de viva voz. Lanza también su hipótesis de que el soma (la famosa bebida de la inmortalidad de los textos védicos) podría ser algún potente enteógeno. Cuenta asimismo su amistad con Roger Heim, micólogo de fama mundial y director del Museo Nacional de Historia Natural de Francia, y finaliza con nuevas referencias a la experiencia mística y visionaria que vivió por primera vez junto a Eva Méndez / María Sabina, la sabia de los hongos, en una aldea perdida de la Sierra de Oaxaca y cómo, en buena medida, aquello cambió su vida.

\subsection{El retorno de los brujos: una primera divulgación}

En 1960, Louis Pauwels y Jacques Bergier publicaban en la prestigiosa editorial Gallimard Matin des Magiciens, un libro de divulgación traducido al español como El retorno de los brujos (1962), que contó con numerosas ediciones (nosotros nos hemos servido de la décima edición en español, aparecida en 1980).

En el prólogo, Pauwels, el inductor del texto, explica su origen. Hijo de un sindicalista utópico que deseaba ardientemente la liberación interior, en su juventud se refugia en el hinduismo de Vivekananda, en el Bhavagad Gita, y se hace discípulo de Gurdjieff y lector de René Guénon. Amigo de André Breton, este le presenta a René Alleau, historiador de la alquimia que, a su vez, le permitirá entrar en contacto con Jacques Bergier, el coautor del libro.

Matin des magiciens es el resultado de cinco años de investigaciones en todos los ámbitos del conocimiento $y$, según sus autores, en las fronteras de la ciencia y de la tradición. En palabras de Pauwels, "he realizado un viaje bastante largo por el mundo de la física, la antropología, las matemáticas y la biología, antes de intentar, una vez más, hacerme una idea del hombre, de su naturaleza, de sus facultades y de su destino" (1980: 20). De forma similar, en ese viaje intentan trascender tanto el materialismo como el espiritualismo, dejándose llevar por la fascinación del esoterismo y de la mística en la búsqueda del lado de la "ultraconsciencia y de la vigilia superior", y creando lo que denominan la escuela del "realismo fantástico". Para los autores, la imaginación, la "verdadera imaginación", es la facultad que les permite bucear y captar la auténtica realidad de las cosas, dejando de lado los filtros impuestos por los hábitos, prejuicios y conformismos intelectuales al uso. Cuando se sigue por este camino, "la ciencia moderna nos enseña que, tras lo simple y visible, está lo invisible y complicado" (op. cit.: 24).

Pauwels y Bergier señalan que el objetivo fundamental del libro es abrir el mayor número de puertas posibles combinando lo que es positivo con lo que es maravilloso entre el universo visible y lo invisible, ya que "existen, tal vez, uno o varios universos paralelos al nuestro" (1980: 27). En las últimas líneas del prólogo, apuntan: "Este libro no es una novela, aunque su intención sea novelesca [...]. Es el relato, a ratos legendario y a ratos exacto, de un primer viaje a los dominios apenas explorados del conocimiento [...], dominios que, por ahora, siguen siendo tierra prohibida" (op. cit.: 28).

De hecho, El retorno de los brujos es una enciclopedia o, mejor dicho, una mezcla de orientación mágico-científica que no supera la marca o el estilo del Reader's Digest. En efecto, los autores hablan prácticamente de todo: de la alquimia y la piedra filosofal; de civilizaciones desaparecidas; de antiguas leyendas y mitos mayas, incas, aztecas, nazcas, quechuas, etc.; de sociedades secretas, tipo Golden Down; de parasicología, e incluso del interés de los nazis por el ocultismo...

Entre los muchísimos autores citados brillan con luz propia los nombres de Gurdjieff, René Guénon, 
Lanza del Vasto, Aldous Huxley, Jung, J. Frazer, el Dr. Fortune (estudioso de los aborígenes australianos), C. Lévi-Strauss, René Alleau... La continua introducción de citas hace que el texto resulte bastante pesado, ya que, bajo la apariencia de una gran erudición, las lecturas realizadas son algo precipitadas y de cara a la galería. Así, muchas afirmaciones y supuestas pruebas científicas son de una notable fragilidad y parecen fundamentadas en el vacío más escandaloso... En fin, que si el libro es tan largo es porque los autores reproducen narraciones completas de Arthur Machen, J. L. Borges, C. Clarke, Walter M. Miller, Gustav Meyrink, H. H. Ewers, el gran Lovecraft o H. G. Wells, por hacer referencia a autores de la literatura fantástica o de ciencia ficción; asimismo, figuran relatos completos de Wolfang Pauli, Rudolf Steiner, H. Blavatsky, Hitler, Jules Romain, W. Blake o Edgar Cayce, en una especie de mezcla pretenciosa que pretende abarcarlo todo y dar respuestas a problemas y temas que aún no la tienen...

A pesar de las valoraciones poco favorables que estamos haciendo, el libro tuvo un gran impacto en el momento de su publicación. Uno de sus epígrafes, por ejemplo, titulado Ciencia sin consciencia: ¿y consciencia sin ciencia? (pág. 47), parece haber inspirado el Congreso de Córdoba de 1979, titulado precisamente Science et conscience: les deux lectures de l'univers, al que nos referiremos más adelante. Por otra parte, el capítulo "Conspiración a la luz del día" (p. 65) es claramente premonitorio de La conspiración de Acuario de Marilyn Ferguson: cuando esta se refiere a los "conspiradores" que hay por todo el mundo para transformar la Consciencia, estos parecen calcados de los "mutantes", "hombres nuevos" u "hombres despiertos" a los que se refieren Pauwels y Bergier, a los que, por cierto, cita una sola vez, aunque con palabras de elogio, la autora norteamericana de La conspiración de Acuario (3).

Finalmente, por su carácter divulgativo, intuimos una clara continuidad entre Matin des magiciens (1960), The Aquarian Conspiracy (1980), el libro de Ferguson, y What the Bleeper Do We Know!? Discovering the Endless Possibilities for Altering Your Everyday Reality (2006), de W. Arntz, B. Chasse y M. Vicente, título de una famosa película y del libro homónimo, traducido el mismo año al español como ¿iY tú que sabes!?

\subsection{Lynn White: la ecología profunda}

Un texto seminal, quizás menos conocido que los anteriores, es el de Lynn White, titulado The Historical Roots of Our Ecological Crisis, publicado en Science en 1967. White, profesor de historia medieval en una universidad norteamericana, señala que fue una conversación con Aldous Huxley, mantenida poco antes de morir, y que califica de inolvidable, el desencadenante de la reflexión que propone sobre el trato desnaturalizado a que el hombre occidental somete la naturaleza.

Según White, las formas de vida humanas modifican los contextos naturales, y algunos ejemplos bien seleccionados ilustran algunos principios básicos de la ecología. Históricamente, es a partir del siglo XVI cuando la tecnología y la ciencia, vinculadas a nombres como Copérnico, Vesalio, Galileo o Newton, adoptan un sello claramente occidental que cristalizará en la Revolución industrial, que cambiará la faz de Europa. En efecto, si el hombre en las formas de vida campesinas medievales aún formaba parte de la naturaleza, con la industrialización se convertirá en su explotador y depredador más feroz.

Ahora bien, según White, que el hombre se sienta y se convierta en el amo despiadado de la naturaleza no es una cuestión puramente vinculada al progreso tecnológico y científico, sino que -y esta es probablemente la mayor aportación del autor -se debe a sentimientos más profundos que él asocia a las formas o creencias religiosas. En efecto, la victoria del cristianismo sobre el paganismo primitivo fue el elemento clave para encauzar esta revolución psíquica. En la antigüedad pagana -continúa White-, cada árbol, cada manantial, río o arroyo, cada colina o cueva de la montaña tenían sus propios genius loci y sus espíritus guardianes. Dichos espíritus acostumbraban a ser accesibles a los hombres, que mantenían un diálogo con ellos; así, cuando se cortaba un árbol, se perforaba una montaña o se desviaba un arroyuelo era indispensable aplacarlos para obtener su beneplácito.

Sin embargo, todo este imaginario animista, según el cual en la naturaleza todo estaba dotado de vida, 
cambió radicalmente con la implantación del cristianismo, según el cual Dios creó al hombre a su imagen y semejanza y lo colocó en el centro y en la cúspide de la creación dándole poderes ilimitados sobre plantas y animales y, en definitiva, sobre todo cuanto existe.

Con este cambio de paradigma religioso, el hombre (occidental), convertido en amo, señor y dueño absoluto de todo, piensa, como cualquier déspota, que puede hacer lo que le venga en gana. Así, el dogma cristiano implantado con arrogancia en los primeros siglos de nuestra era legitima la concepción de que la única razón de ser de la naturaleza es servir al hombre, pues Dios lo coronó, ab initio, como único rey de la Creación.

Esta herencia tan ferozmente antropocéntrica ha tenido escasas excepciones: el ejemplo más claro es el de Francisco de Asís, que se identificaba con todas las criaturas de la Tierra y consideraba hermanos y hermanas a las hormigas, las flores o el fuego, y según la leyenda convenció a un lobo feroz hasta convertirlo en una bestia mansurrona. Desgraciadamente, esta opción de "humildad cósmica" representada por el Poverello ha sido la excepción que confirma la regla, de modo que las consecuencias de lo que White denominó hace 45 años los orígenes históricos de nuestra crisis ecológica son cada vez más inquietantes y devastadoras.

\subsection{Abraham Maslow: las experiencias cumbre}

En 1968, el psicólogo estadounidense Abraham H. Maslow publicaba Toward a Psychology of Being, traducido al español como El hombre autorrealizado. Hacia una psicología del ser (1972) y que nosotros hemos manejado en su decimoquinta edición, aparecida en 2003.

En este libro, Maslow presenta los fundamentos de la psicología humanista, que sugiere una tercera vía frente a la psicología behaviorista (objetiva y metamórfica) y el freudismo ortodoxo. Entiende esta Tercera Psicología (las mayúsculas son siempre del texto original) como una weltanschaung global que supone una nueva concepción del hombre y también una filosofía específica de la vida. En ella los aspectos transpersonales y transhumanos adquieren un papel relevante, ya que se trata de una visión "centrada en el cosmos más que en el bien y las necesidades del hombre, que trasciende la naturaleza del hombre, su identidad, autorrealización, etc." (Maslow 2003: 8).

Maslow se alinea junto a pensadores y psicólogos estadounidenses como Thoreau, Whitman, William James y John Dewey, y señala que para vivir necesitamos algo "superior a nosotros mismos", pero alejado de cualquier dogmatismo eclesial. Subraya el término "autorrealización", sinónimo de "plenitud humana" que, a su vez, implica el pleno desarrollo de nuestra naturaleza, fundamentada más en la biología que en la cultura. Así pues, Maslow, sin rechazar las bases puestas por el psicoanálisis y por la psicología experimental (o behaviorismo) de raíces científico-positivas, propone lo que denomina "superestructura eupsíquica", que entiende como una psicología del Ser, metamotivacional y que debe integrar los fundamentos de las dos ramas hegemónicas en la búsqueda de la verdad total.

Maslow alinea esta tercera fuerza o vía con los seguidores de Adler, Rank y Jung, así como con los neofreudianos o posfreudianos, recogiendo también elementos de la terapia gestalt y de la psiquiatría existencial. En el prólogo de la primera edición de Toward a Psychology of Being, el autor confiesa que fue Aldous Huxley quien lo convenció de tomar en serio la psicología de la religión y del misticismo.

Una de las partes más influyentes del libro es la tercera, que se presenta como una compilación de artículos, conferencias y ponencias en congresos dedicada a la presentación y análisis de las experiencias cumbre (peak experiences), que el autor también denomina experiencias clímax, trascendentales o de éxtasis. Explica que las descripciones que sirven para caracterizarlas las obtuvo a partir de las entrevistas mantenidas con un total de ochenta individuos y de las respuestas enviadas por otros 190 universitarios (posiblemente alumnos del propio Maslow, aunque esto no se explicita).

Estos estados, característicos de las personas autorrealizadas, implican unos momentos de extrema 
felicidad y plenitud -que también califica de amor del Ser o conocimiento del Ser- que se diferencian de otras formas de amar caracterizadas por el déficit. Entre los rasgos que Maslow (4) señala como característicos de las experiencias cumbre está la capacidad de trascender el propio yo, la sensación de completitud, unicidad y perfección, la capacidad para captar de manera diáfana aquellas verdades eternas de las que nos habla la philosophia perennis, la semejanza de la autorrealización con otras experiencias de tipo místico, amoroso o estético y, en fin, la experiencia gozosa y plena del todo. En cita textual: "Llegados a este punto, puede contemplarse lo que [se] ha descrito como una fusión del ego, el id, el superego y el ideal del ego, el inconsciente y el preconsciente, los procesos primarios y secundarios; como una síntesis del principio del placer con el principio de la vida; como una regresión saludable carente de temores, al servicio de una mayor madurez; una verdadera integración de la persona a todos los niveles" (Maslow 2003: 131).

\subsection{Carlos Castaneda: el aprendiz de chamán}

En 1968, un estudiante de Antropología de la Universidad de los Ángeles, Carlos Castaneda, publicaba The Teachings of Don Juan (A Yaqui Way of Knowledge), traducido algunos años después al español con el título de Las enseñanzas de Don Juan (1974) con un magnífico prólogo de Octavio Paz.

En este libro, Castaneda cuenta cómo conoció a Don Juan, un viejo indio yaqui, mago y brujo, que se convierte en su maestro iniciático. La instrucción, iniciada en 1961, implicará una estrecha relación entre el discípulo y el maestro en la que la autoridad del segundo sobre el primero será total. El aspirante obtendrá de su maestro sabiduría y poder, y aprenderá unos secretos que solo aquel controla. La experiencia hay que llevarla a cabo con respeto y temor, ya que a menudo lo que se aprende es peligroso. Para convertirse en "hombre de conocimiento" hay que seguir el "camino del guerrero", que, además, es "un camino que tiene corazón", expresiones empleadas por Don Juan para referirse al largo itinerario iniciático por el que transita Carlitos, uno de los neófitos elegidos para impregnarse de su concepción mágica de la realidad.

En esta, el chamán y brujo yaqui sumerge a su discípulo en una "realidad no ordinaria"; y la mejor manera de hacerlo es a través de las experiencias alucinógenas: con peyote o "mezcalito", con setas alucinógenas o con datura, la raíz de un cactus difícil de localizar pero que Don Juan conoce bien. La ingesta de estos elementos rituales y sagrados puede provocar vómitos, convulsiones y temblores; por otra parte, el uso y la doma (en el sentido de domesticación) de las plantas para obtener su espíritu puede resultar largo y fatigoso. Al final del proceso, sin embargo, espera al novicio una sabiduría no ordinaria que confiere poder a quien la posee y desea.

El caso de Carlos Castaneda, seguido por otros como Michael Harner o, entre nosotros, por Josep $\mathrm{M}^{\mathrm{a}}$ Fericgla, es el del antropólogo que se convierte en chamán y se sumerge en un universo mágico y religioso de tipo animista. Esta nueva concepción se caracteriza por integrar y estrechar los lazos entre el mundo mineral, vegetal, animal, humano y sobrehumano. De manera complementaria, las facultades humanas (mundo interior y exterior), los estados de vigilia y de sueño, el ámbito empírico y el imaginario, todo, absolutamente todo, está interconectado, de modo que no es difícil concebir la existencia de una única energía que recorre el cosmos, esa totalidad viva, global y holista que integra por igual los elementos del macrocosmos y del microcosmos.

Según Octavio Paz, en el denso prólogo titulado La mirada anterior, el tema del libro de Castaneda es la derrota de la antropología y la victoria de la magia, ya que si bien el texto se inicia como un trabajo de etnografía sobre plantas alucinógenas, a las pocas páginas se convierte en la historia de una conversión. Así, la dualidad sujeto/objeto -un sujeto que conoce y un objeto para conocer- se desvanece, y en su lugar aparece la dualidad maestro/neófito. En la relación inicial -continúa Paz-, el antropólogo quiere conocer al otro; más tarde, el neófito quiere convertirse en otro. Esta conversión implica dejar de ser antropólogo para convertirse en brujo y poder acceder así a otro tipo de conocimiento, un conocimiento depreciado por Occidente y por la ciencia contemporánea. 
Los medios para acceder a ese conocimiento son las drogas utilizadas por los indios americanos desde hace miles de años: el yagé o ayahuasca de Sudamérica, el peyote del altiplano mexicano y las setas enteógenas de las montañas de Oaxaca y Puebla, o la datura, que Don Juan hace experimentar a Castaneda en el primer libro de la trilogía. De esta forma, el antropólogo-brujo penetra en una tradición caracterizada por las experiencias visionarias que estaba en vías de extinción. Octavio Paz, que demuestra ser un buen conocedor de este mundo, compara la ingesta de enteógenos como mecanismo de iluminación espiritual con las prácticas ascéticas cristianas, la meditación oriental o la danza sagrada de los derviches giróvagos, todos ellos medios para obtener un objetivo idéntico: la liberación interior, la visión y la auténtica sabiduría. En este despertar a la otra realidad (el segundo libro de la tetralogía (5) se titula precisamente $A$ Separate Reality. Further Conversations with Don Juan, 1971, traducido al castellano como Una realidad aparte. Nuevas conversaciones con Don Juan, 1974), Castaneda muestra la consistencia (y la lógica de esta visión mágica y prodigiosa del mundo, esta "mirada anterior" que, recordemos, da título al prólogo de O. Paz) que permite al estudiante de antropología convertido en brujo captar esa visión unitaria del mundo y vivir otra vida, pero otra vida que está aquí. Podríamos añadir que el lector, gracias a los textos de Castaneda, descubre aquella concepción primigenia de la realidad que, en palabras de Huxley (que ya hemos recordado en páginas anteriores), nos permite captar ese oscuro conocimiento de que "todo está en todo y que todo es realmente cada cosa", fundamento y esencia de la magia y el chamanismo.

\subsection{Fritjof Capra: física y misticismo}

En 1975, un físico teórico austriaco, Fritjof Capra, profesor en Berkeley, publicaba un libro de temática pionera, The Tao of Physics (6), subtitulado en español Una exploración de los paralelismos entre la física moderna y el misticismo oriental (2007). Al principio del libro, Capra narra una experiencia profunda que le llevó a escribirlo. Dice así:

"Estaba yo una tarde de verano sentado frente al océano, con el sol ya declinando. Observaba el movimiento de las olas y sentía al mismo tiempo el ritmo de mi respiración, cuando de pronto fui consciente de que todo lo que me rodeaba parecía estar enzarzado en una gigantesca danza cósmica. [...] sentado en aquella playa, mis anteriores experiencias [como físico] cobraron vida: «vi»» cascadas de energía que llegaban del espacio exterior, en las que las partículas eran creadas y destruidas siguiendo una pulsación rítmica; «vi» los átomos de los elementos y los de mi cuerpo participando en aquella danza cósmica de energía; sentí su ritmo y «oí» su sonido, y en ese momento supe que aquella era la Danza de Shiva, el Señor de los Danzantes adorado por los hindúes" (Capra 2007: 19-20).

Interesado como estaba por el misticismo oriental -principalmente por el hinduismo, el budismo (particularmente el zen) y el taoísmo- Capra desarrollará en El Tao de la física las muchas analogías existentes entre la física moderna y la filosofía del lejano Oriente. Pero estos paralelismos no se encuentran solo en los vedas y el I Ching o en los sutras del budismo, sino también en fragmentos de Heráclito, en el sufismo de Ibn Arabi o en las enseñanzas del brujo yaqui Don Juan (Matus). Veámoslo con más detalle.

La ciencia moderna se fundamentó, desde sus inicios, en la formulación de un dualismo extremo espíritumateria. La visión de la naturaleza de René Descartes establecía la existencia de dos reinos separados e independientes: la res cogitans (la mente), por un lado, y la res extensa (la materia), por otro. Posteriormente, la física newtoniana no hizo más que reforzar las dualidades alma/cuerpo, espíritu/materia y yo/el mundo en que se apoya la física clásica.

Frente a esa visión mecanicista del mundo -continúa Capra-, la concepción oriental es "orgánica", pues para el místico las cosas y los acontecimientos captados por sus sentidos están estrechamente interconectados y no dejan de ser aspectos o manifestaciones de una misma realidad última. Por otro lado, todos y cada uno de estos objetos, eventos, etc. tiene un carácter fluido que se caracteriza por un 
cambio perpetuo. El conocimiento de esta unidad básica del Universo es el elemento central del misticismo oriental, y su meta más elevada consiste en llegar a comprender y experimentar esta realidad a través de un estado de consciencia expandido como es el de la iluminación.

A principios del siglo $\mathrm{XX}$, las investigaciones experimentales sobre el átomo dieron unos resultados sensacionales que no estaban previstos. Lejos de ser las partículas duras y sólidas que el hombre había imaginado desde la antigüedad clásica, los átomos se revelaron como unos espacios vacíos en que unas partículas extremadamente pequeñas -los electrones- giraban en torno a un núcleo. De este modo, en torno a 1920, nacía la teoría de los cuanta sobre la que apoya la física moderna, que revela, a diferencia de la física newtoniana válida para el mundo atómico -no para el subatómico-, la unidad básica del universo. De esta idea también se desprende la imposibilidad de descomponer el mundo en pequeñas unidades dotadas de existencia independiente.

El libro de Capra El Tao de la física está dedicado a demostrar la tesis de que la realidad, en física y en mística, es una energía fluida en perpetua transformación. Hay que decir que el autor logra plenamente su objetivo comparativo, ya que el libro atrapa desde el primer momento incluso a aquellos lectores que, como nosotros, desconocemos los fundamentos técnicos de la teoría de la relatividad y de la física cuántica. Asimismo, pese a que tampoco somos intérpretes de las teorías de Einstein y Heisenberg, Capra tiene la habilidad de hacernos comprender la semejanza de la posición de estos respecto a la interpretación del cosmos que desarrolla, por ejemplo, el lama tibetano Govinda.

En síntesis: la idea matriz que caracteriza tanto a la filosofía oriental como a la física moderna es que en el seno del universo las cosas están interconectadas y son parte indisociable de una única totalidad. El hindú expresa esta totalidad mediante la metáfora de la Danza de Shiva, mientras que el físico lo hace a través de la teoría del campo cuántico. Ambas, insiste este profesor de física, "el dios danzante y la teoría física, son creaciones de la mente: modelos que describen la intuición de sus autores sobre la realidad" (Capra 2007: 65).

\subsection{El Congreso de Córdoba: ciencia con consciencia}

En una línea muy parecida a la desarrollada por Fritjof Capra, el director de una cadena de radio, France Culture, Yves Jaigu, organizaba en 1979 en Córdoba un congreso multidisciplinar bajo el título de Science et Conscience: les deux lectures de l'Univers (7) cuyas contribuciones se publicaron en 1980.

Kathleen Raine, autora de una ponencia sobre William Blake, escribe que para este visionario el error radical de la civilización moderna ha sido separar el espíritu de su objeto: la naturaleza. En efecto, en la historia occidental, y principalmente desde el siglo XIX, como resultado del positivismo que invade el pensamiento científico, se refuerzan aún más las dualidades cartesianas de la res cogitans y la res extensa, matrices de la física clásica.

Sin embargo, como ya hemos visto más atrás, desde A. Einstein, con su teoría de la relatividad, la física cuántica y el desarrollo de la neurofisiología, los límites de la racionalidad empiezan a tambalearse y el campo del conocimiento se extiende hacia ámbitos como la sincronicidad o la transmisión de pensamientos y muchos otros fenómenos físicos o psíquicos considerados hasta entonces pura fantasía. De esta manera, las viejas dualidades cuerpo/espíritu, materia/alma empiezan a ser percibidas desde perspectivas menos rígidas que las habituales hasta entonces. Por otra parte, y como consecuencia de los trabajos de Heisenberg, Bohr o Bell y del desarrollo de la mecánica y la física cuántica en general, también cambia el papel que se atribuye al observador de los fenómenos observados y, en definitiva, se diluyen las fronteras de lo que se ve como real o, mejor dicho, de los vínculos que unen lo que es sensible con lo inteligible.

Para debatir sobre estas y otras cuestiones, France Culture convocó en Córdoba, cuando ocupaba su alcaldía el político comunista Julio Anguita, un congreso que contó con la participación de algunas de las primeras espadas de la física y la neurociencia, pero también del psicoanálisis o de la historia de las 
religiones: David Bohm (profesor de física teórica en la Universidad de Londres), Karl Pribram (profesor de neurociencia en Stanford), Fritjof Capra (profesor de física teórica en Berkeley, al que nos hemos referido anteriormente), algunos premios Nobel, y otros representantes de la psicología, como James Hillman, del Instituto Jung de Zúrich, Gilbert Durand, director del Centre de Recherche sur l'Imaginaire, o Leon Azkénazi, gran conocedor de la cábala judía e investigador del Centro de Estudios Judíos de Jerusalén. Entre los numerosos observadores invitados se puede citar a Carlos Castilla del Pino, catedrático de psiquiatría de la Universidad de Córdoba.

Michael Cazenave, uno de los organizadores, señala (pp. 11-12) que algunos de los grandes interrogantes que se plantearon en el encuentro fueron los siguientes:

1. ¿Se puede avanzar la hipótesis de la existencia de una unidad psíquico-física potencial del conjunto del universo (lo que los filósofos medievales llamaban el Unus Mundus)?

2. ¿Es posible (formular) la hipótesis de una consciencia-energía fundamental cuyos fenómenos físicos, fisiológicos, psíquicos e inconscientes serían los diferentes modos de manifestación, y lo que Henry Corbin llamaba lo imaginal, la puerta de entrada?

3. ¿Se puede considerar la coexistencia de una materia y una consciencia ontológicamente diferentes, pero en constante interacción?

4. ¿Hay que considerar el universo solo bajo el ángulo del azar y la necesidad o también se puede pensar como un lugar donde se dan fenómenos de sentido como los que redescubren las teorías de la física moderna o los psicólogos de las profundidades?

Estos y otros interrogantes fueron algunos de los grandes temas que se debatieron en este original y posiblemente poco conocido Congreso de Córdoba, que perseguía un claro objetivo: encontrar una nueva episteme, multidisciplinar y dialógica, con la que poder encarar algunos de los enigmas que condicionan a los hombres de ciencia y de pensamiento, sin las habituales y rígidas fronteras disciplinares.

\subsection{Marilyn Ferguson: el manifiesto de la New Age}

En 1980, la periodista y psicóloga norteamericana Marilyn Ferguson publicaba The Aquarian Conspiracy, traducida al español como La conspiración de Acuario (1994), con prólogo de Salvador Pániker. Este libro ha sido considerado habitualmente como el manifiesto por excelencia de la llamada Nueva Era o New Age.

De entrada, la autora cita alguno de los elementos apriorísticos de carácter ideológico:

"El paradigma de la Conspiración de Acuario concibe a la humanidad enraizada en la naturaleza. Promueve la autonomía individual en el seno de una sociedad descentralizada. Nos considera administradores de todos nuestros recursos, internos y externos. No nos ve como víctimas ni como peones, no nos considera limitados por condiciones ni condicionamientos, sino herederos de las riquezas de la evolución, capaces de imaginación, de inventiva, y sujetos de experiencias que apenas si hemos llegado a entrever todavía" (Ferguson 1994: 31, cursiva en el original).

Según Ferguson, la naturaleza humana no es ni buena ni mala, sino abierta, en tanto que se halla inmersa en un continuo proceso de transformación y trascendencia, y es necesario que se descubra a sí misma. En este proceso juegan un papel clave la intuición, el sentir y la necesidad de un cambio profundo, personal y cultural, pero, sobre todo, el hecho de lanzarse, como recomienda la autora, a la "aventura espiritual" que es la Conspiración de Acuario.

La conspiración tiene precedentes ilustres: místicos y esotéricos como el Maestro Eckhart, Pico della 
Mirandola, Jacob Boehme, Swedenborg o William Blake; los reformadores inconformistas, radicales y conservacionistas de la Escuela Transcendentalista norteamericana, como Ralph Waldo Emerson o Henry David Thoreau; pacifistas como Gandhi o M. Luther King; algunos grandes escritores, como Hawthorne, H. G. Wells, Kazantzakis o Aldous Huxley; psicólogos y psiquiatras como David Riesman, Erich Fromm o Carl Rogers; pensadores heterodoxos como Joseph Campbell, Carlos Castaneda, Gregory Bateson, Theodore Roszak, y un largo etcétera que incluye, como ya se ha dicho, a Pauwels y Bergier. Más adelante se referirá a autores influyentes y precursores de la nueva conciencia, como Abraham Maslow, Hermann Hesse y J. Krishnamurti, con una referencia muy clara a California como epicentro de la conspiración y, muy especialmente, a la comuna de Esalen, donde impartían cursos A. Watts, A. Toynbee, P. Tillich, Rollo May y muchos otros.

En el capítulo IV, titulado "La transición: gentes de cambio", la autora diseña el perfil o retrato robot de los posibles seguidores de la conspiración. Este incluye un amplio abanico de tipos: los que practican el biofeedback, el psicodrama y las estrategias de expansión de conciencia; los que participan en las redes de los movimientos de autoayuda o de ayuda mutua; los que meditan (sea cual sea la técnica o la escuela elegida); los que disfrutan con los cuentos sufíes, con los bailes de los derviches y con los koans zen o llevan diarios de sueños o han hecho los cursos de ángeles. También son posibles conspiradores los simpatizantes de la teosofía, la terapia primal o bien los que practican diversas terapias corporales, desde el yoga hasta las artes marciales; los que han buscado experiencias intensivas de cambio personal y colectivo en Esalen, en Big Sur; y, en fin, todos aquellos que desean fervientemente un cambio deliberado de conciencia.

Para alcanzar la transformación, Marilyn Ferguson señala que es preciso pasar por cuatro etapas: la primera es preliminar y fortuita, pero proporciona un medio de acceso; la segunda etapa, para los que siguen adelante, es de exploración; en la tercera, una etapa de integración, el conspirador aprende a confiar en su "gurú interno" y a vivir en el misterio; finalmente, en la cuarta etapa, la de la conspiración propiamente dicha, se descubren otras fuentes de poder y la manera de usarlo en beneficio propio y de los demás. Muchos conspiradores, además, tienen la sensación de que tienen una misión que cumplir en esta vida y, deseosos de encontrar un cojín de fraternidad, se orientan hacia redes más amplias de ayuda mutua.

El principio teórico o filosófico que guía este movimiento se fundamenta en las "estructuras disipativas", denominación acuñada por el científico que las descubrió, el belga llya Prigogine, que fue distinguido con el Nobel de Química en 1977 por su hallazgo. Según explica Salvador Pániker en el prólogo, Prigogine llamó "estructuras disipativas" a aquellos sistemas abiertos cuya estructura se mantiene por una continua disipación de energía. Este continuo intercambio de energía con el entorno crea la posibilidad de un "reordenamiento" brusco hacia una mayor complejidad. Este nuevo paradigma -continúa Pániker- pone de relieve la importancia de lo aleatorio e irreversible, así como el carácter creativo de la propia naturaleza, idea que en buena medida concuerda con la concepción taoísta de una autoorganización espontánea. De esta manera, la "conspiración" (etimológicamente, "reunión de los que respiran conjuntamente") de la que habla Ferguson es: "el nuevo sesgo de la aventura humana: articular los antagonismos desde un nuevo lugar meta, generar una nueva racionalidad, reencantar el mundo, apuntar a lo improbable. Son muchos quienes exploran en esta nueva dirección. Son los miembros invisibles de la llamada Conspiración de Acuario" (Pániker 1994: 11, subrayado en el texto).

Marilyn Ferguson dedica buena parte de su libro a la presentación de este potencial de transformación y refiere y defiende un amplio abanico de nuevos paradigmas: por ejemplo, el "nuevo paradigma respecto del poder y la política"; el "nuevo paradigma de la salud", también de la educación y del aprendizaje; los nuevos paradigmas científico-económicos, etc. En todos los casos compara sistemáticamente los rasgos que caracterizan el funcionamiento de los viejos paradigmas frente a los nuevos y explica cómo la adopción de estos últimos puede suponer un cambio personal profundo y también en el sistema de valores.

En síntesis, la autora invita a los lectores a sumarse al grupo de los conspiradores y a buscar un nuevo orden que sea válido tanto para el individuo como para el mundo en el que vive. 
Lástima, sin embargo, y esto ya es valoración nuestra, que la lectura de The Aquarian Conspiracy (como ya nos había pasado con Matin des Magiciens) tenga un tufo de fast food intelectual y emocional de primer orden. La autora ofrece recetas de todo tipo a diestro y siniestro, y maneja una gran cantidad de datos que trata con un notable grado de superficialidad y trivialidad y que carecen, casi siempre, de una mínima profundidad teórica. Todo esto, junto con la permanente actitud de bricolaje y de collage ecléctico y descafeinado que adopta Marilyn Ferguson, hace que su bestseller, pese a las traducciones y la influencia mediática que ha tenido, esté a años luz de los otros clásicos que integran esta sección.

\subsection{Salvador Pániker: retroprogresión y mística}

Salvador Pániker, buen conocedor de la filosofía occidental y oriental, publicaba en 1982 Aproximación al origen, un libro muy original en el que defiende la tesis según la cual el avance tanto del individuo como de las sociedades se fundamenta en un doble movimiento simultáneo hacia el futuro y hacia el origen al que denomina retroprogresivo.

El autor, que hace suya una metáfora de W. H. Auden, quien en 1947 hizo famosa la expresión The Age of Anxiety, prefiere modificarla y hablar de "la era de la depresión": "Mi hipótesis general es que del mismo modo que las depresiones individuales (exógenas) pueden interpretarse como respuestas a una pérdida de lazos afectivos, la depresión inherente a nuestra cultura corresponde a la pérdida de relación con el origen, con la «realidad»" (Pániker 2001: 51).

Ahora bien, ¿qué es el origen? El origen, según el autor, es la no dualidad previa a la escisión entre pensamiento y ser. El origen es lo absoluto y, como tal absoluto, es no pensable. El gran camino para acercarse a lo que es primordial, para buscar el origen, es el de la mística. Romain Rolland hablaba del "sentimiento oceánico" para referirse a esta experiencia primaria de unidad que, en su caso, ejemplificaba en la relación del niño con el pecho de su madre.

La tesis, insistentemente repetida por Pániker, es que hay que volver al origen, a la no dualidad, con toda la ambivalencia o paradoja que ello supone, ya que el auténtico progreso es lo que él llama "retroprogreso".

Que el origen supone la no dualidad es el fundamento de todas las corrientes místicas, empezando por la hindú. Según Pániker, la mística es una de las grandes tradiciones subterráneas, fundamentada en el hermetismo y la analogía, como dice Octavio Paz, y que, como subcultura subordinada, se opone a las corrientes hegemónicas que han cristalizado en iglesias y estados.

La salud, en un sentido amplio, consiste en conciliar estas dos orientaciones y en conseguir, según expresión de Maslow, "a new kind of human being" que sea capaz de moverse entre la capacidad creadora de vivir en la incertidumbre y la capacidad mística de reconciliarse con el origen. Superar esta brecha o fisura es el reto por excelencia que el autor se plantea en este texto.

Pániker señala que el atractivo de la sabiduría oriental -y, más concretamente, del budismo, el taoísmo, el vedanta y el yoga- consiste en que ofrece un modelo de cultura que, a diferencia de la ética judeocristiana, no contempla el pecado original y, por tanto, tampoco los intensos mecanismos de culpa y sublimación asociados. Estos son un lastre considerable para enfocar el auténtico camino de lo retroprogresivo, que, como ya se ha dicho, consiste en la construcción innovadora de un futuro que implica reconsiderar el pasado como única vía para acceder a él. Y en este proceso crítico se encuentra esa cosa terapéutica que desde siempre ha estado allí: la no dualidad.

Pániker cree también que esta nueva orientación que propone implica, además de otra conciencia de ambivalencia, el acceso directo del sujeto a la misma realidad, ser la propia realidad (op. cit.: 266), sin los intermediarios habituales que empleamos para acercarnos a ella, principalmente la vía simbólica. De esta forma, la mística se define como: 
"lo real, inexpresable simbólicamente [...] lo cual no conduce a suspender la vida sino a vivirla de otro modo, desde la más honda libertad a la que tiene acceso el hombre [...] un súbito desaprendizaje, eliminación de mediaciones, mecanismos de defensa, interpretaciones, teorías, adherencias [...]. Llámese satori, llámese samadhi, llámese como se quiera, esa libertad o salud es algo que cada cual ha de encontrar por sí mismo y al margen de toda enseñanza" (Pániker 2001: 288, subrayado en el original).

Así pues, para acceder a la experiencia mística ("la mística -nos dice el autor parafraseando Picasso- no es una búsqueda: se encuentra", p. 295), hay que descodificar la conciencia; debemos deshacernos de todos aquellos códigos previos -el mismo símbolo del yo- y de todo lo que se ha ido interponiendo y que nos impide esa visión prístina de la realidad original.

Según el autor, es posible reconciliar el camino occidental de la exploración crítica con el camino oriental de la liberación interior. Esta es posiblemente la vía que Aldous Huxley, el autor con quien hemos iniciado el tema, denominaba philosophia perennis y que, en una nueva cita textual: "podría resumirse así: cabe desvelar una última realidad llamada Brahmán, Tao, Dharmakaya, Deidad, Origen, o como se prefiera. Lo que todos los místicos han enseñado es el posible acceso, a través de una vía no simbólica, a esta última realidad. En el límite se trata de una experiencia pura, transparencia del significado sin significante" (Pániker 2001: 287, subrayados en el original).

Salvador Pániker defiende, pues, el retorno a la mística -lo que hay en el origen, la no dualidad-para hacerla compatible con la ciencia y el símbolo, realidades claramente ancladas en la dualidad. Eso mismo, aunque con matices, es lo que seguirá defendiendo en dos libros posteriores -Ensayos retroprogresivos (1987) y Filosofía y mística. Una lectura de los griegos (1992)- dotados del mismo carácter riguroso y estimulante que caracteriza a Aproximación al origen, texto con el que cerramos el epígrafe dedicado a los clásicos.

\section{El estudio de la New Age y las ciencias sociales en España}

Para finalizar el artículo, dedicaremos un último apartado a preguntarnos cuál ha sido el interés de los científicos sociales españoles -principalmente antropólogos y sociólogos- por estudiar la nebulosa místico-esotérica, la New Age o, de acuerdo con nuestra terminología, los nuevos imaginarios culturales. Avancemos que un primer balance nos indica que el interés, por ahora, es muy escaso. En cualquier caso, vamos a comentar, unas veces telegráficamente y otras con mayor extensión, lo que conocemos y hemos leído sobre esta temática.

Un antropólogo catalán, Jordi Moreno, se convirtió en uno de los pioneros en esta materia al dedicar en 1994 un artículo al "ámbito difuso de lo mistérico". En él, tras presentar el campo de análisis, al que denomina "religiosidad amorfa y magmática", se centra en los grandes temas que lo integran y desarrolla la tesis de que se trata de un vasto sistema metafórico, canalizado y vivificado por un tipo de pensamiento analógico conectado a través de la tautología.

Ese mismo año Manuel Delgado publicaba otro artículo, también en catalán, titulado "Els nous moviments religiosos" (1994). A pesar de la denominación -reservada normalmente en la literatura especializada para referirse a las "sectas"-, el autor incluye un amplio epígrafe titulado "De la contracultura a la New Age" en el que analiza la nueva sensibilidad que "ha incorporado al gran cóctel místico, el tarotismo, las recetas para (alcanzar) el éxito personal, el culto a la Vida Sana, la música étnica y la ecología, produciendo esta espiritualidad para yuppies que se conoce como «new age»" (1994: 61). Si a estas características sumamos la vulgarización del cientifismo, la convicción ultrapragmática sobre el "poder de la mente", la mezcla de temas ocultistas, teosóficos y ufológicos, todo ello sazonado con los arquetipos del inconsciente colectivo de Jung, tendremos una visión aproximada de lo que el autor entiende por "nuevos movimientos religiosos".

Otro experto en "sectas" y nuevas formas religiosas, José Ma Mardones, publicó en 1997 un texto titulado 
"Nueva espiritualidad y renacimiento religioso. Características de la nueva religiosidad emergente". En él sitúa el origen de la espiritualidad New Age en un momento de crisis y pérdida del monopolio institucional cristiano. Los rasgos definitorios de la nueva religiosidad son: 1) un ecumenismo envolvente (en el sentido de considerar como igualmente válidas todas las religiones existentes), 2) las buenas relaciones con la ciencia, 3) la realización o salvación canalizada por la vía de la armonía interior y con el todo, 4) la inmersión en la conciencia universal y el esoterismo como experiencia transpersonal y totalizante. El autor destaca el decisivo papel que juegan en estas hierofanías la emoción, la recreación religiosa individual, la experimentación de lo vivido y el carácter poscristiano del fenómeno. Estos y otros temas ya aparecían en las "Conclusiones abiertas" de un libro del propio Mardones titulado Para comprender las nuevas formas de religión (1994).

En una línea similar cabría situar los trabajos de otros expertos en historia, fenomenología y hermenéutica de las religiones que, como Manuel Guerra (1998), Juan Bosch (2001), Francisco Díez de Velasco $(2000,2006)$ o Lluís Duch $(1990,1995,1997)$, se han referido a temáticas similares a la que aquí nos interesa.

Con una base más empírica e incorporando trabajo de campo, María del Mar Griera y Ferran Urgell, miembros del ISOR (Investigación en Sociología de la Religión de la Universidad Autónoma de Barcelona), dirigido por Joan Estruch, publicaban Consumiendo religión. Nuevas formas de espiritualidad entre la población juvenil (2002). El trabajo previo constó de 15 entrevistas a profesionales y otras 30 a jóvenes consumidores de prácticas no convencionales, así como de una observación participante (y no participante) sobre las conductas religiosas de jóvenes de Sabadell. Los autores hicieron suya la definición de un tal C. Danneels y, bajo el título de "Un mar de dudas", abordaban o sintetizaban su objeto de estudio como sigue:

"No es religión, pero es por lo menos religiosa; no es una filosofía, pero es por lo menos una visión del hombre y del mundo, así como una clave de interpretación; no es una ciencia, pero se apoya en leyes científicas, aunque haya que ir a buscarlas entre las estrellas. New Age es una nebulosa que contiene esoterismo y ocultismo, pensamiento místico y mágico respecto a los secretos de la vida, y una pizca de cristianismo, todo revuelto con ideas que proceden de la astrofísica" (2002: 40).

Si el libro de Griera y Urgell constituye uno de los hitos en el panorama socioantropológico español, también la obra de Anna Fedele, investigadora italiana que hizo su doctorado en la Autónoma de Barcelona, ocupa un lugar destacado. En el año 2004, Fedele presentó su tesis de máster, titulada inicialmente María Magdalena en la Nueva Era y luego publicada como El camino de María Magdalena. Un recorrido antropológico por la ruta del peregrinaje de la nueva espiritualidad (2008). La primera parte del libro es un amplio recorrido histórico que tiene como eje la figura de la protagonista, mientras que la segunda parte, titulada "El camino de María Magdalena, entre el cristianismo, el neopaganismo y la New Age", presenta la espiritualidad feminista y neopagana centrada en la misma figura y con una buena cobertura teórica proporcionada por dos de los grandes expertos en la New Age: Wouter Hanegraaff (1996) y Paul Heelas (1996), autores de obras ya clásicas.

El arquetipo de la Magdalena es también el eje de fondo de su tesis doctoral, titulada Mary Magdalene. Menstrual Blood and Mother Earth. An Anthropology of Spiritual Feminist Pilgrimages in Contemporaty France and Catalonia, defendida en el otoño de 2007 en la Autónoma de Barcelona. En este nuevo texto, muy elaborado y cuidado, la autora nos describe tres peregrinaciones -una catalano-española, otra italiana y una tercera angloamericana- hacia la gruta de la Sainte Baume con un análisis minucioso de los rituales, la liturgia y los aspectos simbólicos relacionados con la sangre menstrual, las diosas madres negras, el neopaganismo, la Wicca, el neochamanismo y la tradición tántrica, y la ecosofía, todo ello vinculado con la espiritualidad femenina y feminista que, de acuerdo con las culturas indígenas y ancestrales, legitimaría aspectos esenciales de la fertilidad de la Tierra y de la sexualidad humana, temáticas abordadas con un especial cuidado por la autora.

Mary Magdalene. Menstrual Blood and Mother Earth se divide en tres grandes partes: antes, durante y después de las peregrinaciones; y las entrevistas efectuadas por la autora a las peregrinas, al igual que 
sus observaciones participantes, constituyen algunas de las mejores páginas escritas en nuestro país sobre el complejo mundo de la New Age. Algunos artículos recientes $(2008,2009)$ redondean el trabajo de Anna Fedele sobre la Magdalena y su simbolismo.

Por encargo del Tradicionari, obra enciclopédica en diez volúmenes, Joan Prat y Jordi Moreno prepararon un texto panorámico con el título de "La nebulosa místico-esotérica" (2007), denominación claramente inspirada en la socióloga francesa, Françoise Champion. Se trata de un recorrido misceláneo que intenta dejar constancia de los aspectos más relevantes relacionados con el tema: se ofrecen unas breves pinceladas históricas sobre los orígenes de la New Age y sobre las características generales de la nebulosa, presentadas a través de las técnicas, métodos y filosofías dominantes. El repaso de algunos textos seminales, como los de F. Lenoir (Les metamorphoses de Dieu, 2003), los numerosos artículos de la ya citada F. Champion, y también de la antropóloga brasileña Deis Siqueira, o de los autores autóctonos $\mathrm{M}^{\mathrm{a}}$ del Mar Griera y F. Urgell, complementan el texto.

Posteriormente, quien firma estas líneas coordinó una investigación conjunta realizada por las siete personas que integramos el GRIC (Grup de recerca sobre els nous imaginaris culturals), que elaboramos la ya citada monografía Els nous imaginaris culturals: espiritualitats orientals, teràpies naturals i sabers esotèrics. La obra se estructura a partir de los tres grandes apartados del subtítulo, ámbitos o pilares sobre los que hemos desarrollado un intenso trabajo de campo durante dos años largos. Como es habitual en los estudios de antropología, centramos una parte de nuestros esfuerzos en la realización de entrevistas en profundidad a los profesionales y usuarios de las espiritualidades orientales, las terapias naturales y los saberes esotéricos. En total, entrevistamos a 69 informantes, y para el tratamiento comparado de los materiales obtenidos acordamos tratar en todas las entrevistas cuatro grandes interrogantes: ¿quiénes son?, ¿qué hacen?, ¿por qué lo hacen? y ¿qué piensa su entorno?

Así pues, cada capítulo consta de una primera parte centrada en los informantes que hemos conocido y entrevistado, titulada Els personatges ('los personajes'), y una segunda dedicada a las observaciones participantes. En este segundo apartado, bajo el nombre de Els escenaris ('los escenarios'), concentramos la etnografía propiamente dicha. También aquí acordamos unos criterios comunes que nos debían facilitar el tratamiento posterior de las observaciones realizadas, y establecimos una ficha con diez campos básicos: 1) Nombre del observador u observadora participante, 2) Tipo de actividad y denominación, 3) Lugar de realización, 4) Fecha y duración, 5) Precio, 6) Nombre de la persona o personas que la imparten, 7) Descripción detallada de la actividad, 8) Público asistente, 9) Valoración personal y 10) Otros. Generalmente, los apartados 7 y 8 (a veces también el 9) son los tratados con mayor extensión y cuidado.

Asimismo, cuando comenzamos a asistir a talleres, seminarios, cursos, conferencias, meditaciones, temazcales, sesiones catárticas diversas, lecturas de cartas del tarot o cartas astrales, etc., nos dimos cuenta de la necesidad de diferenciar la observación participante convencional de otras que acabamos por designar como experiencias participantes. La distinción es muy sencilla, y un pequeño ejemplo la aclarará: si uno de nosotros asistía a la conferencia de una neochamana, discípula de Michael Harner, a la que seguía una sesión de curación, y después elaboraba el informe etnográfico preceptivo, esto era, sin más, una observación participante. Ahora bien, si a la mañana siguiente, el mismo observador participante comenzaba un taller titulado "La senda del chamán", que podía durar todo un fin de semana (o la semana entera), y participaba, como cualquier otro neófito, de todas las actividades y ejercicios propuestos, a esto preferimos llamarlo experiencia participante, ya que el nivel de implicación personal y vivencial era mucho mayor y más intenso que en el primer caso. Con esto, evidentemente, no pretendemos sentar cátedra, pero sí constatar que a nosotros la distinción nos ha resultado cómoda y útil.

Un total de 70 eventos, entre observaciones y experiencias participantes, constituyen la base etnográfica que nos sirvió para redactar los escenarios de las espiritualidades orientales, las terapias naturales y los saberes esotéricos.

De Tarragona podemos pasar a la Universitat de València, donde al menos dos profesores, Gil Manuel 
Hernández y Miguel Ángel Ruiz, ambos del Departamento de Sociología y Antropología Social, han demostrado interés por el tema. Del primero, Gil Manuel, hemos leído dos artículos, "El error trascendente. La cultura en el laberinto existencial del ser humano" (2008-2009) y "Hacia una nueva trascendencia global: globalidad, espiritualidad y humanidad" (s. f.), además de la recensión de un libro de Jean Shinoda Bolen. Todos ellos son de una potencia intelectual inusual. Sus planteamientos para el abordaje de los nuevos paradigmas están cargados de sugerencias, de modo que no podemos sino recomendar vivamente al lector que disfrute de su finura analítica.

Por su parte, Miguel Ángel Ruiz, junto con dos colaboradores mexicanos, ha iniciado un trabajo de campo sobre la New Age en Chiapas. Una primera publicación relacionada con dicha temática es "Consumidores alternativos: turismo étnico y espiritualidad new age en los procesos de reinvención del imaginario urbano en San Cristóbal de las Casas, México" (2011), donde analizan la oferta terapéutica en la órbita de la nueva era articulada con la tradición indígena, pero también con las espiritualidades budistas o chamánicas. Los autores se preguntan si dicho fenómeno de sincretismo variado es un puro proceso de mercantilización de lo alternativo étnico y espiritual o, por el contrario, caben también otras interpretaciones.

Algunas páginas atrás nos hemos referido a la tesis doctoral sobre María Magdalena llevada a cabo por Anna Fedele. Además de la original presentación de la New Age por parte de esta investigadora italiana, conocemos otras tesis doctorales que abordan el tema, bien de forma tangencial, bien directamente. En la primera modalidad se puede encuadrar la tesis de Javier Eloy Martínez, profesor de la Universidad Miguel Hernández de Elche, quien la defendió en la UNED de Madrid con el título de Artes marciales: ¿arte, defensa personal, religión o deporte? Un análisis sociocultural del Taekwondo en la provincia de Alicante (2008). Se trata de un trabajo muy exhaustivo donde el autor aborda la temática general de las artes marciales procedentes del este asiático (China, Japón y Corea) desde una perspectiva global. Tras realizar una aproximación histórica y describir la estructura institucional y jerárquica del taekwondo, analiza las relaciones sociales que se generan para, finalmente, delimitar los aspectos religiosos, filosóficos, doctrinales, simbólicos y artísticos de la disciplina. La unidad de observación privilegiada es el gimnasio, lugar perfectamente conocido por Eloy Martínez, primero como usuario y practicante del arte marcial y después como antropólogo y observador participante.

Otra tesis, en este caso presentada en el Departamento de Filosofía de la Universidad de La Laguna, es la de Ricardo Campo, titulada La New Age: esoterismo, ocultismo y pensamiento alternativo (2010). Para su autor, la New Age, como paradigma del saber alternativo, se asienta sobre tres grandes pilares o ejes, que son la astrología, las medicinas alternativas y el ecologismo; y presta una atención especial a la ufología, el esoterismo y el ocultismo. La visión panorámica trazada por Ricardo Campo, muy influida a nivel teórico por Wouter Hanegraaff, es una de las más completas que conocemos en la literatura española especializada, solo comparable al libro de Vicente Merlo, La Ilamada (de la) Nueva Era (2007), que comentaremos en breve.

La tercera tesis que queremos reseñar, todavía en fase de elaboración, es la de Eugenio Porras, quien en agosto de 2009 presentó un proyecto con un doble título: Tras los pasos de Don Juan. Miradas etnológicas a los neochamanismos amerindios o Del chamanismo a los neochamanismos: transacciones espirituales en la globalización. Independientemente de cuál sea el título definitivo, lo que sí parece claro es que este etnólogo español que trabaja en el Instituto Nacional de Antropología e Historia de México (en la sede de Tepic, Nayarit) es quien mejor entiende el mundo neochamánico, principalmente el relacionado con los tarahumaras y los huicholes. Los que conocemos el proyecto de Eugenio Porras, ya elaborado en los años noventa, aguardamos con impaciencia y expectación el resultado final de sus investigaciones y reflexiones sobre el tema, que de momento no han cristalizado en algo concreto.

Reflexionar teóricamente sobre lo que se ha vivenciado previamente -o aún se vive- es el común denominador de los tres autores a los que vamos a aludir a continuación: Vicente Merlo, Josep $M^{a}$ Fericgla y Emilio Fiel. Los tres, además de practicantes de diversas disciplinas, son ideólogos indiscutibles de los nuevos imaginarios culturales. 
Ya nos hemos referido en líneas anteriores al filósofo Vicente Merlo para señalar que su libro La Ilamada (de la) Nueva Era. Hacia una espiritualidad místico-esotérica (2007), tantas veces citado, había sido una guía imprescindible para nuestra propia investigación y que hicimos nuestros, con leves modificaciones, los tres grandes ejes que presenta: la dimensión oriental, la dimensión psicoterapéutica y la dimensión esotérica. Cada dimensión es tratada con un conocimiento de causa envidiable (principalmente la primera y la tercera), y su prólogo de carácter autobiográfico, titulado "Fragmentos de una memoria viva", es un ejemplo de honestidad y buen hacer modélicos. Otros libros de Merlo dignos de mención son Las enseñanzas de Sri Aurobindo (1998), de quien el autor se considera discípulo, La autoluminosidad del atmán (2001) y La fascinación de Oriente (2002).

Josep $M^{a}$ Fericgla, doctor en Antropología, es otro experto muy reconocido, tanto a nivel práctico como teórico, en el ámbito de los estados alterados o expandidos de consciencia. Dirige la colección Cogniciones, de la editorial La Liebre de Marzo, colección especializada en plantas, hongos o sustancias alucinógenas, psicodélicas o enteógenas. También dirige la Sociedad de Etnopsicología Aplicada y Estudios Cognitivos y preside la Fundación que lleva su propio nombre, instituciones que organizan, normalmente en la sede central de Can Benet Vives, cursos especializados de fin de semana sobre temas y experiencias diversas ordinarias o no ordinarias.

Además de esta actividad que podríamos calificar de ejecutiva, Txema Fericgla es autor de una obra notable sobre estados expandidos de consciencia y chamanismo. Esta arranca con uno de sus primeros libros, El bolet i la gènesi de les cultures (1984), posteriormente traducido al castellano y publicado en la colección ya citada, en la que también han aparecido otros títulos, escritos o coordinados por él mismo, como Plantas, chamanismo y estados de conciencia (1994), Al trasluz de la ayahuasca. Cognición, oniromancia y consciencias alternativas (1997) y Los enteógenos y la ciencia (1999). Otros libros que se sitúan en una línea similar, aunque quizás más teóricos, son El sistema dinámico de la cultura y los diversos estados de la mente humana. Bases para un irracionalismo sistémico (1989) y los dos volúmenes sobre Estados modificados de conciencia, psicoterapia y conocimiento, que sirven como libros de texto (u obras de consulta) para los matriculados en un seminario que anualmente se celebra con el mismo título. El primer volumen lo coordina el propio Fericgla y el segundo, José Carlos Bouso, psicólogo clínico y uno de los colaboradores habituales de Can Benet Vives.

La obra de Fericgla, sin embargo, es muy variada y se completa con algunos otros títulos, como Els jívaros, caçadors de somnis. Diari d'un antropòleg i vivència xamànica a través de l'aiahuasca entre els Shuar (1994), dietario del autor que refleja su iniciación chamánica entre los jíbaros de la Amazonia ecuatoriana y que fue traducido poco después al castellano. Asimismo, cabe citar Los chamanismos a revisión. De la vía del éxtasis a Internet (2000), que incluye un completo y útil apéndice que lleva por título "Breve historiografía de la antropología de los enteógenos y las sanaciones con especial énfasis en las ediciones en lengua castellana". Finalmente, en Epopteia. Avanzar sin olvidar. Respuesta a las cuestiones más frecuentes tras vivir una experiencia transformadora (2003), describe y analiza lo que denomina "EXACES" (experiencias activadoras de estructuras), vinculadas a otro de los seminarios de Fericgla, seguramente el más concurrido y un hito en su ya dilatada trayectoria: el Taller de integración vivencial de la propia muerte.

El tercer autor del que nos vamos a ocupar es Emilio Fiel, Miyo, un gurú carismático que lleva más de 30 años trabajando en el ámbito del crecimiento interno y la evolución de las conciencias. Fundador de la comunidad del Arcoirisy, posteriormente de la Escuela ChrisGaia, ha impulsado numerosos proyectos a través de seminarios, cursos, conferencias, rituales colectivos, etc., lo que no le impide escribir sin descanso. En efecto, Emilio Fiel es autor de una decena de libros publicados en la colección Ensueños de Cristal, dirigida por él mismo. Dada la imposibilidad de comentarlos todos, nos centraremos en los dos primeros y, principalmente, en el que inaugura la colección, titulado El Sol que mora en las tinieblas $\left(1^{\mathrm{a}}\right.$ edición de 2006 y $3^{a}$ de 2011).

Se trata de un texto programático en el que Emilio Fiel desarrolla las tesis principales de un pensamiento muy personal en el que hace gala de un extraordinario conocimiento de la mitología universal, de la historia de las religiones y de las tradiciones teosófica, esotérica y ocultista; con todo ello y gracias a una 
habilidad sincrética de primer orden, ha creado un universo simbólico y esotérico a su medida. Este universo es expuesto de forma clara y contundente en sus libros, donde rechaza de forma explícita los usos académicos convencionales. Quizás por este motivo el pensamiento del autor es difícilmente sintetizable, aunque al escucharlo de viva voz o al leerlo, uno capta la lógica interna de su proceder y pensar, siempre alternativos a lo que comúnmente se practica y se cree. En la contraportada de este primer volumen se pregunta: “¿Dónde se esconde nuestra luz? [y contesta] En el corazón de nuestra oscuridad". A continuación, sintetiza:

"La tenemos invertida en angustias, miedos, rencores, rechazos, dudas. Y hemos de bajar al vientre para recuperarla de nuevo pero ya transmutada en conciencia. Este cuerpo es nuestra materia divina y el medio para realizarnos como dioses encarnados. Ésa es la misión: llenarlo de luz en el corazón de cada célula y vencer la mentira de la muerte. Para ello la mejor manera de disolver la dolorosa atadura que sufrimos con la forma humana es cuadrar nuestros balances entre la luz y la oscuridad. Eso nos permitirá ser de nuevo seres fluidos capaces de fundirnos empáticamente con cada uno de los cinco reinos de la naturaleza: mineral y vegetal, animal y humano, además de los seres dévicos o angélicos del universo que YoSoy. De ese modo la columna de fuego de los chakras, el resplandor del cuerpo luminoso y la reconexión del ADN, unirán sus fuerzas para facilitar nuestro proceso de ascensión física, más allá de la quinta dimensión hasta las fronteras de la undécima, que está a nuestra disposición en estos momentos en la historia planetaria. Los trabajos internos de kundalini, la meditación profunda, el servicio desinteresado, la ensoñación consciente, el amor mágico, las ceremonias de sanación planetaria, el uso de la crisis como maestras, nuestro vínculo con la Madre Tierra y sus elementos, la hermandad con seres estelares y de otras dimensiones nos reconocen como seres capaces de generar luz y conciencia en cada momento y por tanto como guerreros y amazonas preparados para la batalla florida contra nuestra propia oscuridad" (texto de la contraportada).

En el mismo libro figura un glosario en el que se explican o definen los conceptos fundamentales que acostumbra a utilizar en sus charlas y escritos.

El segundo volumen, Cabalgando el dragón del vientre, subtitulado La limpieza del subconsciente y la recapitulación de la sombra (2009), aborda aspectos más concretos, relacionados con las técnicas y métodos específicos para alumbrar esa luz interna en medio de las propias tinieblas. Otros títulos de la colección Ensueños de Cristal son Los exploradores del Crepúsculo, Devas y Naturaleza mágica y El camino con corazón.

Volviendo ahora al ámbito académico más convencional y visualizando los intereses de las nuevas generaciones de antropólogos y antropólogas que conocemos, todo parece indicar que uno de los temas estrella es la fascinación que ejerce la ayahuasca. Al menos cuatro investigadores han realizado sus tesinas o tesis de máster o de final de carrera en esta dirección.

El primer trabajo, y por ahora el más completo, es el de Santiago López Pavillard, titulado Recepción de la ayahuasca en España (2007-2008), presentado en la Universidad Complutense de Madrid. El autor introduce la ayahuasca como brebaje amazónico consumido en diversos contextos rituales; su llegada a España y la actual situación de ilegalidad; las grandes modalidades de consumo, incluido el religioso de la Iglesia del Santo Daime y de la Unio do Vegetal; la descripción de los asistentes en las sesiones de toma de ayahuasca en las que el propio López Pavillard ha participado, sin que falten amplios extractos de entrevistas a guías y usuarios de dicho enteógeno.

Otra investigación, en este caso un trabajo final de grado en Humanidades de la Universitat Oberta de Catalunya, es el de Jordi Corbera, que lleva por título L'ayahuasca ara $i$ aquí: usos rituals de l'ayahuasca a Catalunya (2012). El ensayo de Corbera, buen conocedor de la bibliografía sobre el tema, se centra en algunas grandes temáticas que desarrolla por separado: las iglesias ya citadas del Santo Daime y de la Unio do Vegetal, los seguidores del Camino Rojo (inspirado en la cosmovisión de los lakotas del norte), los chamanes y curanderos americanos que a menudo viajan a Cataluña, España o Europa, los "guías" occidentales, así como los terapeutas que trabajan adicciones. La tipología que el autor plantea sobre 
rituales, ceremonias y escenarios centrados en la substancia, y la descripción de los escenarios etnográficos de los que ha formado parte como observador o experimentador participante, completan esta investigación laboriosa y muy profesional.

Un alumno del máster en Antropología de la Universidad Miguel Hernández de Elche, Víctor Rodríguez, presentó como tesis final una Aproximación a las prácticas neochamánicas en Alicante y Murcia (2011). En ella analiza un grupo de Google, Activa Alicante, cuyos intereses giran en torno a temas neochamánicos. Asimismo, describe dos ceremonias, una purificación a través de un temazcal y otra de toma de ayahuasca. El autor, de quien hemos perdido la pista, nos comentó su interés por realizar la tesis doctoral en el centro dirigido por Jacques Mabit, Takiwasi, en Tarapoto (Perú), donde la ayahuasca se utiliza como sustancia terapéutica.

El último trabajo que conocemos es el de Raquel Ariza, alumna del máster en Salud de la Universitat Rovira i Virgili, titulado El abrazo de la ayahuasca. El proceso de conversión a mujer-medicina, todavía en fase de elaboración, en el que se cuenta la historia de Montse, la informante principal, y su proceso de conversión -o el abrazo- que esta vivió después de descubrir los poderes de la ayahuasca, que, junto con el San Pedro, el peyote y la marihuana, ha incorporado en sus prácticas curativas como mujer-medicina.

Aquí finalizamos nuestro recorrido expositivo, con la vaga esperanza de que la lectura de estas páginas sobre los nuevos imaginarios culturales estimule a algún investigador o investigadora a lanzarse al ruedo y plantearse alguna nueva investigación sobre este mundo tan fascinante como desconocido.

\section{Notas}

1. Hemos utilizado una versión francesa (La philosophie éternelle, Plon, París, 1948) que habíamos conocido mucho antes que la traducción castellana de Edhasa (2000) y la catalana de Pagès Editor (2008).

\section{Posteriormente fue reeditado por RBA (Barcelona, 2006) en su colección Sabiduría Oriental.}

3. Marilyn Ferguson (1994: 58) escribió: "En El retorno de los brujos, bestseller publicado en Francia en 1960, Louis Pauwels y Jacques Bergier describían la «conspiración abierta» formada por individuos inteligentes transformados por sus propios descubrimientos interiores. Según Pauwels y Bergier, los miembros de esta red podrían estarse erigiendo en dispensadores contemporáneos de una larga cadena de conocimientos esotéricos".

4. En el texto de 2003 señala 18 puntos característicos de la experiencia cumbre, pero en otro artículo titulado "La experiencia núcleo-religiosa o trascendental" señala un total de 25. Este segundo artículo se incluye en el libro de Aldous Huxley, A. H. Maslow, R. Bucke y otros titulado La experiencia mística y los estados de conciencia (1980), con selección y prólogo de John White.

5. Además de los dos libros ya citados, forman parte del conjunto Viaje a Ixtlan. Las lecciones de Don Juan (1975) y Relatos de poder (1976). Los cuatro fueron publicados por Fondo de Cultura Económica de México. Los datos corresponden a las ediciones castellanas.

6. En la publicación del Congreso de Córdoba "Science et Conscience" que se presenta a continuación figura también un texto titulado "Le Tao de la physique", versión reducida y muy precisa del libro. Antes de leerlo, nosotros ya conocíamos esta excelente síntesis a cargo del propio Fritjof Capra.

7. Recuérdese que casi veinte años antes Pauwels y Bergier, en Matin des magiciens, habían escrito un epígrafe titulado "Ciencia sin consciencia: ¿y consciencia sin ciencia?" que parece haber inspirado la 


\section{Bibliografía}

Arntz, William (con Betsy Chasse y Mark Vicente)

2006 ¿iY tú que sabes!? Madrid, Palmyra.

Beckford, James A.

1984 "Holistic Imagery and Ethics in New Religions and Healing Movements", Social Compass, XXXI, $\mathrm{n}^{\circ}$ 2-3: 269-272.

Bosh, Juan

2001 "La New Age i l'increment dels esoterismes" en Joan Estruch (ed.), Les noves formes de religiositat. Barcelona. Cruïlla, Fundació Joan Maragall.

Campo, Ricardo

2010 La New Age: esoterismo, ocultismo y pensamiento alternativo. Tesis doctoral. La Laguna. Universidad de la Laguna.

\section{Capra, Fritjof}

1975 El Tao de la física. Málaga, Sirio, 2007

1980 "Le tao de la physique", Science et conscience: les deux lectures de l'univers: 43-53.

Carozzi, María Julia

1999 "La autonomia como religión: la nueva era", Alteridades (Antropologia de los movimientos religiosos), $\mathrm{n}^{0}$ 18: 19-38.

Castaneda, Carlos

1968 Las enseñanzas de Don Juan. Una forma Yaqui de conocimiento. México, Fondo de Cultura Económica, 1974.

1971 Una realidad aparte. México, Fondo de Cultura Económica, 1987.

1972 Viaje a Ixtlán. México, Fondo de Cultura Económica, 1985.

1974 Relatos de poder. México, Fondo de Cultura Económica, 1985.

Champion, Françoise

1989 "Les sociologues de la post-modernité religieuse et la nébuleuse mystique ésoterique", Archives des Sciences Sociales des Religions, vol. 67, n 1: 155-169.

1990 "La nébuleuse mystique-ésoterique", en Françoise Champion y Danièle Hervieu-Lèger (ed.), De l'emotion en religion. Renouveaux et tradition. Paris, Centurion: 17-69.

1993 "La croyance en l'alliance de la science et de la religion dans les nouveaus courants mystiques et ésoteriques", Archives des Sciences Sociales des Religions, n 82: 205-222.

1994 "La 'nébuleuse mystique-ésoterique': une décomposition du religieux entre humanisme revisité, magique, psychologique", en Jean-Baptiste Martin y Françoise Laplantiné (dirs), Le défi magique (I) Esoterisme, occultisme, espiritisme. Centre de Recherches et d'Études Anthropologiques, Presses Universitaires de Lyon.

Delgado, Manuel

1994 "Els nous moviments religiosos". L'Avenç, nº 185: 58-63.

Díez de Velasco, Francisco

2000 Las nuevas religiones. Madrid, Ediciones del Orto.

2006 Breve historia de las religiones. Madrid, Alianza Editorial. 


\section{Duch, Lluís}

1990 Temps de tardor. Barcelona. Publicacions de l'Abadia de Montserrat.

1995 Religión y mundo moderno. Madrid, PPC.

1997 Antropología de la religió. Barcelona, Publicacions de l'Abadia de Montserrat.

Escandell, José J.

2005 "La Nueva Era de Acuario, una nueva humanidad: La auténtica fachada de la Conspiración de Acuario, de Marilyn Ferguson", Arbil, nº 89.

Estrada, Álvaro

1977 Vida de Maria Sabina, la sabia de los hongos. México (España, Argentina, Colombia), Siglo Ventiuno Editores.

Estruch, Joan (ed.)

2001 Les noves formes de religiositat. Barcelona, Cruïlla.

Fedele, Anna

2007 Mary Magdalena, Menstrual Blood and Mother Earth. An Anthropology of Spiritual Feminist Pilgrimages in Contemporary France and Catalonia. Universitat Autònoma de Barcelona. Tesis Doctoral Europea.

2008 El camino de María Magdalena. Un recorrido antropológico por la ruta del peregrinaje de la nueva espiritualidad. Barcelona, Integral/RBA Libros.

"Sur le chemin de Marie Madeleine. Des lectures au pèlegrinage", Quaderns-e 7.

(http://www.icantropologia.org/quaderns-e).

2009 "From Christian Religion to Feminist Spirituality: Mary Magdalene Pilgrimages to La SainteBaume, France", Culture and Religion, vol. 10, n³: 243-261, november. Routledge.

Fericgla, Josep Maria

1985 El bolet i la gènesi de les cultures. Barcelona, Alta Fulla.

1989 El sistema dinámico de la cultura y los diversos estados de la mente humana. Barcelona. Cuadernos de Antropología, Anthropos.

1994 Els jívaros, caçadors de somnis. Diari d'un antropòleg i vivència xamànica a través de l'aiahuasca entre els Shuar. Barcelona, La Campana.

1994 Plantas, chamanismo y estados de conciencia. Barcelona, Los libros de la liebre de marzo.

1997 Al trasluz de la ayahuasca. Antropologia cognitiva, oniromancia y consciencias alternativas. Barcelona, Los libros de la liebre de marzo.

1999 Los enteógenos y la ciencia. Nuevas aportaciones científicas al estudio de las drogas. Barcelona, Los libros de la liebre de marzo.

2000 Los chamanismos a revisión. De la via del éxtasis a Internet. Barcelona, Kairós.

2004 Epopteia. Avanzar sin olvidar. Respuestas a las cuestiones más frecuentes tras vivir una experiencia transformadora. Barcelona. La liebre de marzo.

2008 Textos. Nivel 1 X Seminario Internacional Estados modificados de Consciencia, Psicoterapia y Conocimiento. Societat d'Etnopsiquiatria Aplicada i Estudis Cognitius.

Ferguson, Marilyn

1994 La conspiración de Acuario. España. Año/Cero, Biblioteca Fundamental.

Fiel, Emilio

2011 El Sol que mora en las tinieblas. Barcelona. Colección Ensueños de Cristal, $\mathrm{n}^{\circ} 1$.

2011 Cabalgando al dragón del vientre. La limpieza del subconsciente y la recapitulación de la sombra. Barcelona. Colección Ensueños de Cristal.

Guerra, Manuel

1998 "Nueva Era (New Age)". Diccionario enciclopédico de las Sectas. Madrid, Biblioteca de Autores Cristianos. 
Griera, Maria del Mar (y Ferràn Urgell)

2002 Consumiendo religión. Nuevas formas de espiritualidad entre la población juvenil.Barcelona, Fundacion La Caixa.

Hanegraaff, Wouter J.

1998 New Age Religión and Western Cultura: esotericism in the Mirror of Secular Thought. New York, State University of New York Press.

Heelas, Paul

1996 The New Age Movement. The Celebration of the Self and the Sacralization of Modernity. Oxford, Blackwell Publishers.

Hernández, Gil Manuel

2008-2009 "El error trascendente. La cultura en el laberinto existencial del ser humano", Pasajes de pensamiento contemporàneo, $\mathrm{n}^{0}$ 29: 101-120.

(s/f) "Hacia una nueva trascendencia global: globalidad, espiritualidad y humanidad", VII Congreso español de Sociología.

Huxley, Aldous

1948 La philosophie éternelle. Paris, Plon.

1956 Las puertas de la percepción. Buenos Aires. Sudamericana.

2007 Moksha. Barcelona / Argentina. Edhasa / Los libros de Sísifo.

Huxley, Aldous (y otros)

1980 La experiencia mística y los estados de conciencia. Barcelona, Kairós.

2003 La experiencia del éxtasis1955-1963. Barcelona, La liebre de marzo.

Jung, Carl G.

1952 "Sincronicidad como principio de conexiones acausales" y "Sobre sincronicidad", Obra completa. La dinámica de lo inconsciente. Vol. 8. Madrid, Trotta, 2004.

Lenoir, Frédéric

2003 Les Métamorphoses de Dieu. Paris, Plon.

Lewis, James R.

1992 "Approaches to the Study of the New Age Movement" en James R. Lewis y Gordon Melton (eds.), Perspectives on the New Age: 1-12.

Lewis, James R. (y Gordon Melton) (eds.)

1992 Perspectives on the New Age. Albany. State University of New York Press.

Mardones, José María

1994 Para comprender las nuevas formas de la religión. La reconfiguración postcristiana de la religión. Estella / Navarra, Verbo Divino.

1997 "Nueva espiritualidad y renacimiento religioso. Características de la nueva religiosidad emergente" en Oleza Le-Senne, Francisco (coord.), Las sectas en una sociedad en transformación. Madrid. Fundación para el anàlisis y los estudios sociales: 132-135.

Martínez, Javier Eloy

2008 Artes marciales: ¿Arte, defensa personal, religión o deporte? Un análisis sociocultural del Taekwondo en la provincia de Alicante. Madrid, UNED (Tesis doctoral).

Maslow, Abraham

2003 El hombre autorrealizado. Hacia una psicología del Ser. Barcelona, Kairós.

Melton, Gordon 
1991 "New thought and the New Age" en James R, Lewis y Gordon Melton (eds.), Perspectives on the New Age: 15-29.

Merlo, Vicente

1998 Las enseñanzas de Sri Aurobindo. Barcelona, Kairós.

2001 La autoluminosidad del âtman: aproximación al pensamiento hindú clásico. Madrid, Biblioteca Nueva.

2002 La fascinación de Oriente. Barcelona, Kairós.

2007 La llamada (de la) Nueva Era. Hacia una espiritualidad místico-esotérica. Barcelona, Kairós.

Moreno, Jordi

1994 "Exilis i absències. Assaigs d'aproximació a l'estudi dels moviments religiosos moderns: l'àmbit difús del mistèric", Revista d'Etnografia de Catalunya, nº 4: 110-131.

Pániker, Salvador

1982 Aproximación al origen. Barcelona, Kairós, 2001.

1987 Ensayos retroprogresivos. Barcelona, Kairós.

1992 Filosofia y mística, una lectura de los griegos. Barcelona, Anagrama.

1994 "Prólogo a la edición española" en Marilyn Ferguson, La conspiración de Acuario. España. Año Cero. Biblioteca Fundamental.

1999 "El modelo retroprogresivo" en Manuel Almendro (ed.), La consciencia transpersonal. Madrid, Kairós: 108-121.

Pauwels, Louis (y Jacques Bergier)

1960 El retorno de los brujos. Barcelona, Plaza and Janes, 1980.

Paz, Octavio

1968 "La mirada anterior" (Prólogo a) C. Castaneda. Las enseñanzas de Don Juan. México, Fondo de Cultura Económia, 1974.

Prat, Joan (y Jordi Moreno)

2007 "La nebulosa místicoesotèrica" Tradicionari, vol VIII, L'Univers màgic. Mites $i$ creences. Enciclopèdia Catalana: 278-289.

Prat, Joan (coord.) (y otros)

(En prensa) Els Nous Imaginaris Culturals. Espiritualitats Orientals, teràpies naturals $i$ sabers esotèrics. Tarragona, Publicacions URV.

Redfield, James

2000 La vision des Andes. Pour vivre pleinement la nouvelle conscience spirituelle. Paris, J'ai lu.

Ruiz, Miguel Àngel (y otros)

2011 "Consumidores alternativos: turismo étnico y espiritualidad new age en los procesos de reinvención del imaginario urbano en San Cristóbal de las Casas, México", en Llorenç Prats y Agustín Santana (coords.), Turismo y patrimonio, entramados narrativos. Pasos. Revista de Turismo y Patrimonio Cultural, no 5: 289-305.

Science et Conscience: les deux lectures de l'univers. Stock, Paris

Siqueira, Deis Elucy

2004 "La laberíntica recerca religiosa en l'actualitat: creences i pràctiques místiques i esotèriques a la capital del Brasil". Revista d'Etnologia de Catalunya, n² 24: 100-129.

Stein, Murray

2004 El mapa del alma según Jung. Barcelona, Luciérnaga. 
Wasson, Robert Gordon

1957 "Magic Mushroom". Life, 10 de junio (versión castellana: En busca del hongo mágico") http://www.imaginaria.org/wasson/wasson.htm).

Watts, Alan W.

1971 El camino del Zen. Barcelona, Edhasa.

1976 El camino del Tao. Barcelona, RBA, 2006.

White, Lynn

1967 "The Historical Roots of Our Ecological Crisis", Science, 155, n. 3767: 1204-1207. 